A microstructure-based elastoplastic model to describe the behaviour of a compacted clayey silt in isotropic and triaxial compression

8

2. Post-doc Researcher

1. Associate Professor

Department of Structural, Geotechnical and Building Engineering

Politecnico di Torino

Corso Duca degli Abruzzi, 24

10129 Torino, Italy

guido.musso@polito.it

\author{
Guido Musso ${ }^{1}$, Arash Azizi ${ }^{2 *}$ and Cristina Jommi ${ }^{3,4}$
}


34 3. Professor

35 Department of Civil and Environmental Engineering,

36 Politecnico di Milano

37 Piazza Leonardo da Vinci, 32

3820133 Milano, Italy

39 cristina.jommi@polimi.it

40 4. Department of Geosciences and Engineering

41 Delft University of Technology

42 Stevin weg 1

43 2628CN Delft, The Netherlands

44 c.jommi@tudelft.nl

45

$46 *$ Corresponding author

47 


\title{
A microstructure-based elastoplastic model to describe the behaviour of a compacted clayey silt in isotropic and triaxial compression
}

\begin{abstract}
The paper focuses on the hydro-mechanical behaviour of an unsaturated compacted clayey silt, accounting for fabric changes induced by drying-wetting cycles occurring at low-stress levels. The response along isotropic compression and triaxial compression (shear) at constant water content was investigated by laboratory tests on both as compacted and dried-wetted samples. Compaction induces a micro-structural porosity pertinent to clay peds and a macro-structural porosity external to the peds. Drying-wetting cycles decrease the micro-porosity and increase the macro-porosity, which reduces the water retention capacity, increases the compressibility and promotes higher peak strengths with more brittle behaviour during triaxial compression. A coupled double porosity elastic-plastic model was formulated to simulate the experimental results. A non-associated flow rule was defined for the macrostructure, modifying a stress-dilatancy relationship for saturated granular soils to account for the increase in dilatancy with suction observed in the experiments. The average skeleton stress and suction were adopted as stress variables. Consistently with model predictions, the shear strength at critical state is not significantly influenced by the degree of saturation or by the hydraulic history. On the other contrary, the higher peak strength, brittleness and dilatancy of the dried wetted samples are mostly explained by their reduced water retention capacity.
\end{abstract}

Number of words: 7300

Number of figures: 15

Number of tables: 4 


\section{Introduction}

According to the standard practice, the engineering requirements for earth constructions are guaranteed by compaction at optimum density and water content, and the design of the earth construction is based on the properties of the soil determined immediately after compaction. To reach the desired density, higher stresses than those imposed by service loads are used, resulting in a material which is highly overconsolidated just after compaction. However, experimental (Take and Bolton 2011) and numerical studies (Kovacevic et al. 2001) suggest the soil response changes over time because of seasonal variations in water pressure causing progressive accumulation of volume strains and leading to a dwindle of dilatancy. Therefore, the maximum shear strength that can be mobilised may reduce from peak values to critical state values, with the consequence that design approaches based on soil parameters detected after compaction might not be on the safe side for the long-term serviceability of the geo-structure.

More reliable design approaches should account for the fact that hydraulic conditions at the boundary of the earthwork evolve continuously after the end of the construction, due to oscillations of both the water level and the relative humidity of the air in contact with the embankment. These both cause oscillations of pore water pressure and suction, which imply periodic drying-wetting cycles for large volumes of the unsaturated portion of the embankment. Daily and seasonal cycles of relative humidity, associated to different sequences of rainy and dry days, can be relevant in continental climates (e.g. Calabresi et al. 2013) and, because of global warming, such cycles are expected to become more severe in the future (Rouainia et al. 2009). Increasing severity of suction oscillations over time, and the previous experimental evidence on softening in the material response, justify why the effects of drying-wetting cycles on the hydro-mechanical behaviour of compacted soils for earthworks deserve careful attention. Besides affecting the maximum strength, drying-wetting cycles are known to increase the permeability and to reduce the water retention capacity of compacted soils (Benson et al. 2007). These effects are unfavourable for the stability of embankments, since higher permeability allows for the propagation of pore pressure changes from the surface to deeper layers, increasing

107 Changes in the hydraulic behaviour of clayey silts have been related to fabric changes, even occurring at constant 108 volume (Cuisinier and Laloui 2004). The clay fraction of these soils is organized into peds ('aggregates' in Ng et al. 109 2017) which plastically shrink over suction increase, while the total soil volume remains constant because of the 110 shielding effect provided by the 'skeleton' of silt particles (Romero et al. 2014). A larger macro-porosity emerges, 111 justifying the increase in permeability and the decrease in water storage capacity. This evolution of the soil fabric and of 
112 the hydraulic behaviour during drying-wetting cycles can be reproduced adequately with double porosity hydro113 mechanical volumetric models such as the one proposed by Azizi et al. (2019). However, to the authors' knowledge, 114 limited attention has been paid to the influence of cyclic wetting and drying on the triaxial compression behaviour of 115 unsaturated compacted soils, although it seems reasonable to infer that the fabric changes responsible for the changes in 116 the hydraulic response will impact also on the mechanical behaviour. Experimental studies by Kemal et al. (2005) (on 117 sand samples), by Rojas et al. (2010) (on clayey silt samples cored from a river embankment a few years after 118 construction), and by Zhang et al. (2016) (on a slightly expansive silty soil) remark that drying-wetting cycles tend to 119 increase the peak soil strength and the post-peak soil brittleness.

121 In this work, we aim at broadening the understanding of the effects of previous drying-wetting cycles on the coupled 122 hydro-mechanical response of compacted clayey silts, including the pre-failure behaviour. The evolution of the 123 microstructure of a soil used in the construction of river embankments is analysed experimentally over different hydro124 mechanical paths, both immediately after compaction and after exposure to drying-wetting cycles. Stemming from the 125 premises on the water retention behaviour in Azizi et al. (2019), the comparison between experimental data on as126 compacted and dried-wetted samples is exploited to describe the mechanical response of the soil, within a double127 porosity elastic-plastic framework. The proposed model is used to simulate the results of drying, isotropic compression 128 and triaxial compression (shear) at constant water content tests on both as-compacted and dried-wetted samples, with 129 the purpose of showing and start quantifying the influence of natural drying-wetting cycles on the lifetime response of 130 embankments made of similar compacted clayey silts.

\section{Soil characterization and sample preparation}

The soil investigated is a clayey silt from Viadana, used in the construction of a full-scale model embankment built for research purposes nearly twenty years ago (see Calabresi et al. 2013). The construction of the model embankment promoted a few studies on this type of material, which is typically used in the reinforcement and construction of flood defences along the Po river (e.g. Nocilla et al. 2006; Vassallo et al. 2007). The clay fraction (particle diameter $d<2$ $\mu \mathrm{m})$ is $20.40 \%$ and the silt fraction $(2 \mu \mathrm{m} \leq d<60 \mu \mathrm{m})$ is $79.60 \%$. The specific gravity is $G_{s}=2.735$, the liquid limit $W L$ is $32.6 \%$, with a plasticity index PI equal to $8.3 \%$. According to ASTM D2487 Viadana clayey silt is a low 
143 The effects of drying-wetting cycles on both the fabric and the hydro-mechanical behaviour were investigated on 144 samples that were statically compacted at a dry density $\rho_{d}=1650 \mathrm{~kg} / \mathrm{m}^{3}$ and a water content $w=20 \%$. This state 145 replicates the construction specification for the model embankment (see e.g. Rojas et al. 2010). The fabric resulting 146 from compaction (Original Fabric, OF) was investigated with Scanning Electron Microscopy (SEM) observations, 147 which showed different aggregations of silt particles and peds of clay particles (Fig. 1). In the macrostructure, between 148 silt particles and between silt particles and peds, the radius of the smallest pores appears to be around $1 \mu \mathrm{m}$ or greater. 149 Within the peds, the pore radii are clearly smaller than $1 \mu \mathrm{m}$. Eight samples were prepared to investigate how the pore 150 network changes as a result of different hydraulic and mechanical histories, using Mercury Intrusion Porosimetry 151 (MIP). Four of them were analysed, respectively, at the compaction state (OF), after first drying (dry-OF) and after 152 loading in oedometer at two different axial net stresses $\left(\sigma_{a x}{ }^{n e t}=98 \mathrm{kPa}\right.$, LL-OF, and $\sigma_{a x}{ }^{\text {net }}=1.6 \mathrm{MPa}$, HL-OF $)$. The 153 other four samples were preliminarily exposed to 6 drying-wetting cycles (6Cyc samples). One of them referred to the 154 dry state (dry-6Cyc), another to the wet one (6Cyc), and other two to loading at $\sigma_{a x}{ }^{n e t}=98$ (LL-6Cyc) $\mathrm{kPa}$ and $155 \sigma_{a x}{ }^{n e t}=1.6 \mathrm{MPa}(\mathrm{HL}-6 \mathrm{Cyc})$. The lower stress level, $98 \mathrm{kPa}$, was chosen to represent typical working stresses in the 156 field, while the higher stress, 1.6 MPa, was chosen to investigate whether mechanical loads could (partially) erase the 157 effects of previous drying-wetting cycles.

159 Full details on sample preparation and on the cyclic hydraulic history simulating drying-wetting in the field are given in 160 Azizi et al. (2019). In summary, drying was imposed by exposing the samples to the laboratory environment having a 161 controlled temperature of $21^{\circ} \mathrm{C}$ and relative humidity of $38.5 \%$, corresponding to a suction $s=128.8 \mathrm{MPa}$, which 162 brought the water content to a minimum of $w \approx 0.4 \%$. After each drying stage, the samples were re-wetted by placing 163 them in the compaction mould and injecting the volume of water needed to bring the water content back to its initial 164 value $(w \cong 20 \%)$. After each drying-wetting cycle, the specimens were wrapped up in plastic bags and kept hanging over distilled water in a closed container for at least 5 days to ensure water content homogenisation. The state of the samples prepared for MIP analyses is reported in Table 1. Their hydraulic and mechanical histories are sketched in Fig. 2.

The volume of the samples decreased along drying and increased along wetting. By convention, volume decrease is associated to increasing volume strains and vice versa. Volume strains increased during the first three drying-wetting cycles (Fig. 3) and were about reversible for a larger number of cycles. Consistently, both the hydraulic behaviour 
172 (water retention and hydraulic conductivity) and the fabric evolved during the first three cycles while remaining stable 173 afterwards (see Azizi et al. 2019 for a detailed discussion).

175 The hydro-mechanical behaviour of the OF and 6Cyc samples was studied along drying, isotropic and triaxial 176 compression at constant water content in a triaxial cell allowing for suction control or measurement. Another eight samples were prepared to this scope, following the same procedure detailed above. The same stress paths were imposed to the $\mathrm{OF}$ and the 6Cyc samples (Table 3) to allow addressing the effects of hydraulic cycles on the following hydromechanical behaviour. According to Blight (1964), the pore pressure distribution within a sample sheared under unsaturated conditions is uniform when the time to failure $t_{f}$ is equal or greater than the time for consolidation $t_{100}$. On the basis of the measured hydraulic conductivity (Azizi et al. 2019) and sample compressibility, $t_{100}$ is expected to be of the order of a few hours or less. Assuming that failure occurs when $\varepsilon_{a}=20 \%$, the axial strain rate imposed during triaxial compression was $\dot{\varepsilon}_{a}=0.25 \%$ / hour, which implies $t_{f}=80$ hours.

184 The values of suction and isotropic net stress imposed during drying and isotropic compression are provided in Table 2. 185 The main details of the experimental procedures concerning both the microstructural characterization and the triaxial tests are provided in Appendix 1, while the experimental results, which justify adopting a double porosity model, are presented in section 4 (microstructural investigation) and 5 (triaxial tests).

\section{Double porosity formulation}

Given the observed fabric of the soil, a double porosity framework was chosen to simulate the results of the hydromechanical tests. Double porosity formulations have been extensively adopted to reproduce the hydraulic (e.g. Barenblatt et al. 1960; Gerke and van Genucthen 1993), hydro-mechanical (e.g. Alonso et al. 1999; Choo et al. 2016) and chemo-hydro-mechanical behaviour (Musso et al. 2013) of geologic materials possessing two dominant families of voids, such as fissures and matrix in reservoir rocks (Warren and Root 1963), or inter-aggregate and intra-aggregate pores in compacted soils (e.g. Della Vecchia et al. 2013). Extended reviews of double porosity models are available in Musso et al. (2013), Mašin (2013) and in Choo et al. (2016).

The basic concept underlying these models is that the porous medium can be modelled as two overlapping continua, or structural levels, commonly named "microstructure" and "macrostructure". The microstructure is identified with the deformable solid aggregates, containing their "micropores". The macrostructure is defined by the pore network made of the voids between the aggregates and it is characterised by the spatial distribution of the aggregates. The two structural 
levels deform according to independent constitutive laws, and they may exchange fluid masses if the fluid pressures in the two domains are different. However, in the following, the assumption is made that sufficiently slow hydromechanical processes occur. This assumption implies that the air and the water pressure are the same in the two structural levels, hence no explicit internal mass transfer conditions are needed for a complete description of the response.

\subsection{Volumetric variables}

210 In the definition of the two overlapping continua, porosity and water content - or void ratio and degree of saturation 211 of the soil are split between the two structural levels. The microstructure is made of the solid particles, having volume $212 V_{s}$, and of the voids within the clay peds, $V_{v m}$. Therefore, the microstructural void ratio $e_{m}$ is defined as:

$$
e_{m}=\frac{V_{v m}}{V_{s}}
$$

214 Since the peds are deformable, $e_{m}$ will evolve with stress or suction (see section 3.3). The macro-structural void ratio $e_{M}$ 215 is the ratio of the volume of voids between peds (inter-peds, or macro-structural volume of voids $V_{v M}$ ) over the total 216 volume of the peds, hence including the micropores:

$$
e_{M}=\frac{V_{v M}}{V_{s}\left(1+e_{m}\right)}
$$

218 The latter definition implies a reference "solid volume" for macroporosity which is not constant over time. Following the derivation given and discussed by Mašin (2013), the total void ratio, $e$, must be consistently written as:

$$
e=e_{m}+e_{M}+e_{m} e_{M}
$$

221 where the third term accounts for the change of the volume of the reference solids considered in the definition of the macroscopic void ratio.

The microstructural degree of saturation $S_{r m}$ is the ratio between the volume of water within the micro-pores $V_{w m}$ and the volume of the micro-pores:

$$
S_{r m}=\frac{V_{w m}}{V_{v m}}
$$

The macrostructural degree of saturation $S_{r M}$ is:

$$
S_{r M}=\frac{V_{w M}}{V_{v M}}
$$

where $V_{w M}$ is the volume of water held outside the peds. The total degree of saturation $S_{r}$ follows:

$$
S_{r}=S_{r M}+\frac{e_{m}}{e}\left(S_{r m}-S_{r M}\right)
$$

230 The water ratio $e_{w}$ expresses the ratio of the volume of water to the volume of solids. The microstructural water ratio $231 e_{w m}$ is: 


$$
e_{w m}=\frac{V_{w m}}{V_{s}}=S_{r m} e_{m}
$$

the macro-structural water ratio $e_{w M}$ is:

$$
e_{w M}=\frac{V_{w M}}{V_{s}\left(1+e_{m}\right)}=S_{r M} e_{M}
$$

and the relationship between the total water ratio and the water ratios of the two domains is:

$$
e_{w}=e_{w m}+e_{w M}\left(1+e_{m}\right)=S_{r m} e_{m}+S_{r M} e_{M}\left(1+e_{m}\right)
$$

\subsection{Water retention}

The total water ratio (eq. (9)) is a function of both the micro-and macro-degree of saturation and void ratio. Adopting two van Genuchten (1980) expressions for the degree of saturation over the main branches of the water retention functions of the micro and the macro porosities (e.g. Durner 1994; Casini et al. 2012; Della Vecchia et al. 2015), the water ratio can be written explicitly as a function of suction in the form:

$$
e_{w}(s)=\left[\frac{1}{1+\left(\alpha_{m} s\right)^{n_{m}}}\right]^{m_{m}} e_{m}+\left[\frac{1}{1+\left(\alpha_{M} s\right)^{n_{M}}}\right]^{m_{M}} e_{M}\left(1+e_{m}\right)
$$

where $n_{m}, m_{m}, \alpha_{m}$ and $n_{M}, m_{M}, \alpha_{M}$ are model parameters describing the micro-structure and the macro-structure response, respectively. Infinitesimal variations of the total water ratio are given by:

$$
d e_{w}=d e_{w m}+d e_{w M}=\left[S_{r m} d e_{m}+e_{m} d S_{r m}\right]+\left[S_{r M}\left(1+e_{m}\right) d e_{M}+e_{M}\left(1+e_{m}\right) d S_{r M}+S_{r M} e_{M} d e_{m}\right]
$$

which measures the changes in water content as a function of changes in the void ratios and degree of saturations of the may occur even at constant water ratio, together with changes in the micro and macro void ratios. The transition between the wetting and the drying branches (and vice versa) is postulated as a linear law between the increment of degree of saturation and the increment of suction, independently for each structural level:

$$
d S_{r}=-k_{s c} d s
$$

where $k_{s c}$ is a model parameter, describing the hydraulic stiffness of the soil over reversible drying-wetting cycles, bounded by the main wetting and drying branches.

Changes in the micro or macro void ratio impact mostly on the air entry value of the corresponding porous network. To account for this evidence, a dependency of the air entry value $1 / \alpha$ on the void ratio is introduced. Simple relationships were chosen relating $1 / \alpha_{m}$ and $1 / \alpha_{M}$ to the micro-structural void ratio $e_{m}$ and to the macro-structural void ratio $e_{M}$ :

$$
1 / \alpha_{m}=\left(e_{m} / e_{m 0}\right)^{c_{m}} / \alpha_{m 0} \text { and } 1 / \alpha_{M}=\left(e_{M 0} / e_{M}\right)^{c_{M}} / \alpha_{M 0}
$$


where $c_{m}$ and $c_{M}$ are model parameters, $e_{m 0}$ and $e_{M 0}$ are the values of $e_{m}$ and $e_{M}$ at as-compacted conditions, and $1 / \alpha_{m 0}$ and $1 / \alpha_{M 0}$ are the initial air-entry values. The empirical laws described by eq. (13) are assumed to hold for both the main drying and the main wetting curves.

\subsection{Stress variables}

265 Two stress variables are employed. The first one is the average skeleton stress, which depends on net stress $\left(\boldsymbol{\sigma}^{\text {net }}\right)$, 266 effective degree of saturation $\left(S_{e}\right)$ and matric suction $(s)$ :

$$
\boldsymbol{\sigma}^{\prime}=\boldsymbol{\sigma}^{n e t}+S_{e} \boldsymbol{I}
$$

Equation (14) defines the average skeleton stress for each structural level (macrostructural skeleton stress $\boldsymbol{\sigma}_{M}^{\prime}$ or microstructural skeleton stress $\boldsymbol{\sigma}_{m}^{\prime}$ ), by using the corresponding effective degree of saturation. The second stress variable is matric suction. Similar stress variables have been adopted by different authors (e.g. Jommi 2000; Tamagnini 2004; Romero and Jommi 2008; Zhang and Ikariya 2011; Zhou et al. 2012; Della Vecchia et al. 2013).

Both thermodynamic and experimental observations (Alonso et al. 2010) consistently show that the effective degree of saturation of interest for the macro-structure is given by the free water filling the macro-voids, and thus for the macrostructure $S_{e M}=S_{r M}$. For the microstructure, the relationship $S_{e m}=S_{r m}$ is assumed to hold.

\subsection{Mechanical model for the microstructure}

276 The microstructure is assumed to behave isotropically. Many double porosity models formulated for unsaturated soils rely on the hypothesis of elastic microstructure (e.g. Gens and Alonso 1992; Alonso et al. 1999; Mašin 2013). However, the experimental data in Azizi et al. (2019) suggest that irrecoverable plastic strains of the peds take place during drying-wetting cycles, triggering changes in the water retention and permeability. Therefore, the elastoplastic model of Azizi et al. (2019) is adopted here. Two yielding mechanisms can be activated, one related to mechanical straining of the peds and the other related to irreversible changes of the microstructural water ratio. The former occurs when the stress path reaches the loading collapse (LC) curve, whereas the latter is triggered if the stress path reaches the suction increase (SI) curve during drying, or the suction decrease (SD) curve during wetting. These yield curves are expressed as:

$$
\text { LC: } p_{m}^{\prime}=p_{m}^{\prime *}, \text { SI: } s=s_{I}, \text { SD: } s=s_{D}
$$

286 Within the elastic domain, the degree of saturation evolves along the scanning curves and the relationship between microstructural volume strain $\varepsilon_{m}$ and stress increments is: 


$$
d \varepsilon_{m}^{e}=\frac{\kappa m d p_{m}^{\prime}}{\left(1+e_{m}\right) p_{m}^{\prime}}
$$

where $\kappa m$ is the elastic compressibility of the microstructure.

If yielding occurs directly on the SI, it induces water ratio changes on the main drying WRC accompanied with hardening of the LC, whereas direct yielding on the SD induces water ratio changes on the main wetting WRC accompanied with softening of the LC. If yielding occurs on the LC, it produces plastic volumetric strains with a coupled outward movement of the SI and inward movement of the SD. The SI and the SD evolve together:

$$
\frac{d s_{I}}{s_{I}}=\frac{d s_{D}}{s_{D}}
$$

294 When yielding occurs due to SI or SD, the hardening law is:

$$
d p^{\prime *}{ }_{m}=h_{l C} p^{* *}{ }_{m} \frac{d s_{I}}{s_{I}}
$$

$h_{l C}$ controls the coupled movement of LC due to SI or SD yielding and $p^{\prime *}{ }_{m}$ is the microstructural mean stress at yield.

The plastic volumetric strains $\left(d \varepsilon_{m}^{p}\right)$ due to yielding of the LC curve are

$$
d \varepsilon_{m}^{p}=\frac{(\lambda m-\kappa m) d p^{\prime *}{ }_{m}}{\left(1+e_{m}\right) p^{\prime *}{ }_{m}}
$$

297 where $\lambda m$ and $\kappa m$ are model parameters. In this case, the hardening law is given by

$$
d s_{I}=h_{S} S_{I} \frac{d p^{\prime *}{ }_{m}}{p^{\prime *}{ }_{m}}
$$

298 where $h_{S}$ controls the coupled movement of SI and SD.

299 The general expression for plastic strain increment can be derived through eqs. (17) and (18):

$$
d \varepsilon_{m}^{p}=\frac{(\lambda m-\kappa m)}{\left(1+e_{m}\right)\left(1-h_{S} h_{l C}\right)}\left(\frac{d p^{\prime *}{ }_{m}}{p^{\prime *}{ }_{m}}-h_{l C} \frac{d s_{I}}{s_{I}}\right)
$$

301 The flow rule for yielding on the SI and on the SD is:

$$
\frac{d \varepsilon_{m}^{p}}{d e_{w m}}=0
$$

While the flow rule for yielding on the $\mathrm{LC}$ curve is:

$$
\frac{d e_{w m}}{d \varepsilon_{m}^{p}}=0
$$

304 Changes of the microstructural void ratio are then written in the form:

$$
d e_{m}=-d \varepsilon_{m}\left(1+e_{m}\right)=-\left(d \varepsilon_{m}^{e}+d \varepsilon_{m}^{p}\right)\left(1+e_{m}\right)
$$


When the suction or the effective stress change, the micro-structural void ratio changes and the WRC of the peds evolves accordingly with eq. (13). Further details on the model and the implications on the evolution of the WRC can be found in Azizi et al. (2019).

\subsection{Mechanical model for the macrostructure}

311 Silty soils show some recurrent specific behavioural trends, which make them different from ideal coarse or finegrained soils (Cui and Delage 1996; Ma et al. 2016; Kim et al. 2016; Ng et al. 2017). While they have a mostly

313 volumetric hardening similar to clays, they typically show non associative elasto-plastic response upon triaxial compression, which is more similar to those of coarser soils. When the over consolidation ratio, defined as the ratio between the maximum and the current net stress, is low (typically smaller than 2.5), shearing is ductile and the soil contracts. Shearing is brittle and accompanied by dilation for greater over-consolidation ratios. Peak strength typically occurs together with maximum dilatancy, and both the peak strength and dilatancy at failure have been found to increase when the degree of saturation decreases (e.g. Cui and Delage 1996; Cattoni et al. 2005), similarly to most types of soils (see, e.g., Zhan and Ng 2006; Yao et al. 2014; Zhou and Sheng 2015 on clays; Fern et al. 2016 on sands; Alonso et al. 2016 on rockfill). The finding is consistent with the original conclusions by Kohgo et al. (1993), who observed that one of the effects of suction is to inhibit sliding between particles.

In general, elasto-plastic models formulated for unsaturated silts adopt non-associative flow rules, but hydro-mechanical coupling has been either not introduced (Cui and Delage 1996; Chiu and Ng 2003) or introduced neglecting the water retention and mechanical role of the clay peds (Ma et al. 2016). Instead, the latter seems to be an important feature to understand and model the behaviour of Viadana silt (Azizi et al. 2019).

The yield function and the hardening rule adopted in the present formulation stem from the Modified Cam Clay Model (Roscoe and Burland 1968) extended to unsaturated states, as described in Jommi (2000), and used among others by Romero and Jommi (2008) and Della Vecchia et al. (2015). The yield function is:

$$
f=q^{2}-M^{2} p^{\prime}{ }_{M}\left(p_{0 M}^{\prime}-p^{\prime}{ }_{M}\right)
$$

329 where $p^{\prime}{ }_{0 M}$ is the pre-consolidation pressure of the macrostructure and $M$ is the slope of the Critical State Line in the $330\left(p_{M}^{\prime}, q\right)$ plane, which is assumed not to depend on suction. Following Jommi (2000) and Gallipoli et al. (2003), the 331 preconsolidation pressure in unsaturated states is the sum of the saturated preconsolidation mean stress $p_{M}^{\prime *}$ depending 332 on the volumetric plastic strains, and a term which introduces the effects of the degree of saturation:

$$
p_{0 M}^{\prime}=p_{M}^{\prime *}+\left(1+b_{1}\left(\exp \left(b_{2}\left(1-S_{r M}\right)\right)-1\right)\right)
$$

333 where $b_{1}$ and $b_{2}$ are model parameters describing the sensitivity of the pre-consolidation pressure to changes in the degree of saturation of the macrostructure. 
335 The volumetric hardening law relates $p_{M}^{\prime *}$ to the plastic volume strains $\varepsilon_{v M}^{p}$ :

$$
\frac{d p_{M}^{\prime *}}{d \varepsilon_{v M}^{p}}=\frac{\left(1+e_{M}\right) p_{M}^{\prime *}}{\lambda M-\kappa_{M}}
$$

336 where $\lambda_{M}$ and $\kappa_{M}$ are the elastic-plastic and the elastic volumetric compressibility of the macrostructure.

338 The flow rule is an original proposal of this work, which is formulated to take into account explicitly the evidence of 339 non-associative behaviour of the silt and the constraining effects of suction in the plastic range. The expression stems 340 from the original contribution of Li and Dafalias (2000) for saturated coarse soils:

$$
\frac{\partial \varepsilon_{v}^{p}}{\partial \varepsilon_{q}^{p}}=d=d_{0}\left[e^{m \psi}-\frac{\eta}{M}\right]
$$

341 where $\varepsilon_{v}^{p}$ and $\varepsilon_{q}^{p}$ are the plastic components of the volumetric and deviatoric strains, respectively, $d_{0}$ and $m$ are model 342 parameters, $\eta=q / p^{\prime}$ is the stress ratio and $\psi$ is the state parameter (Been and Jefferies 1985):

$$
\psi=e-e_{c}\left(p^{\prime}\right)
$$

where $e$ is the current void ratio and $e_{c}$ is the void ratio at critical state for the current mean effective stress.

As remarked, a few works point out that dilatancy in unsaturated conditions is higher than in saturated ones. However, assuming dependency on suction only would imply very high (theoretically infinite) dilatancy for dry conditions. Therefore, dilatancy is assumed to increase with the inner constraint induced by the hydraulic component of the skeleton stress, through the product of the effective degree of saturation times suction. Li and Dafalias (2000) expression is also modified so to account for pure volumetric plastic strains occurring along isotropic compression paths. The proposed extension of eq. (27) to the unsaturated state for the macrostructure reads then:

$$
d=\frac{d_{0}}{\eta M}\left(\exp \left(\gamma S_{r M} S\right)\right)\left[e^{m^{m}}-\frac{\eta^{M}}{M}\right]
$$

where $\eta_{M}=q / p^{\prime}{ }_{M}$ is the stress ratio of the macrostructure and $\gamma$ is the additional model parameter weighting the relevance of suction and degree of saturation on the deviatoric response.

\section{Evolution of the pore size density in light of the double porosity framework}

The description of the microstructural and macrostructural void ratio is based on the MIP measurements taken at the different conditions outlined in Table 1. Bimodal Pore Size Density (PSD) functions were detected in all cases, and their evolution with drying-wetting cycles and loading is presented in Fig. 4. Drying-wetting cycles affect the soil fabric 
by shifting the size of the pores corresponding to the dominant peak to a larger pore radius $(r=609 \mathrm{~nm}$ for the OF sample, while $r=917 \mathrm{~nm}$ for the 6Cyc sample), by reducing the frequency of the pores of the dominant mode and by increasing the size and frequency of the pores belonging to the minor mode (Fig. 4a, see also Azizi et al. 2019). Mechanical loading of both OF and 6Cyc samples (Figs. 4b and 4c) reduces the frequency of the pores having radii larger than the one of the peak of the dominant mode. Increasing the load also leads to a progressive decrease of the size of the larger pores belonging to the minor mode. Pores on the left of the dominant peak were not affected by loading. Upon loading, the radius of the dominant peak of the OF samples remains fixed at $r=609 \mathrm{~nm}$ (Fig. 5b), while it progressively decreases from $r=917 \mathrm{~nm}$ to $r=609 \mathrm{~nm}$ for the 6Cyc samples (Fig. 4c). Interestingly, under the axial stress of 1.6 MPa the PSDs of the HL-OF and of the HL-6Cyc samples overlap very well (Fig. 4d), which suggests that the effects imparted on the fabric by the hydraulic history can be almost erased by high mechanical loads.

\subsection{Modelling the Pore Size Density data}

372 A criterion discriminating between intra-peds pores and inter-peds pores allows using the PSDs to evaluate the values of the microstructural void ratio $e_{m}$ and of the macrostructural void ratio $e_{M}$, as observed in various previous work (e.g. Delage and Lefebvre 1984; Cuisinier and Laloui 2004; Monroy et al. 2010). Here, the threshold between intra-peds and inter-peds pores was set to correspond to the radius of the peak of the dominant mode, consistently with Azizi et al. (2019), which allowed reproducing the evolution of the water retention behaviour of compacted Viadana silt.

The microstructural void ratio is evaluated as

$$
e_{m}=\int_{3.5}^{R_{t}} \frac{P S D(r)}{r \ln (10)} d r+0.04
$$

where $3.5 \mathrm{~nm}$ is the smallest pore radius intruded by MIP, $R_{t}$ is the threshold radius separating intra-peds from interpeds pores and 0.04 is the void ratio corresponding to the very small non intruded pores, assumed to be equal to the residual water ratio obtained at very high suctions. The macrostructural void ratio $e_{M}$ was evaluated applying eq. (3), by subtraction from the known total void ratio, $e$. The values of the $e_{m}$ and $e_{M}$ for each of the samples investigated are provided in Table 3 .

The experimental evolution of the total void ratio $e$, of the micro-structural void ratio $e_{m}$ and of the macro-structural void ratio $e_{M}$ along the drying-wetting cycles and the mechanical loading is provided in Fig. 5. Drying-wetting cycles reduced the micro-structural void ratio leaving the total void ratio substantially unaffected. As a result, the macrostructural void ratio increased. Note that the 6Cyc samples were more compressible than the OF samples when 
loaded to $98 \mathrm{kPa}$, suggesting that the larger macro-porosity developed during the preliminary drying-wetting cycles was prone to collapse under small mechanical loads. However, the void ratio of both types of samples under the stress of 1.6

$391 \mathrm{MPa}$ is about the same.

\section{Hydro-mechanical behaviour of Viadana silt in unsaturated conditions and model predictions}

The hydro-mechanical behaviour of Viadana silt in unsaturated conditions, as detected through drying, isotropic and triaxial compression tests run in a suction controlled triaxial cell, is presented together with the predictions obtained with the double-porosity model introduced in Section 3. The calibration of the parameters of the model is described first.

\subsection{Calibration of model parameters}

402 The procedure for the calibration of the parameters of the double porosity water retention model and of the mechanical model for the micro-structure is explained in detail in Azizi et al. (2019). Water retention parameters for both the microstructure and the macrostructure were determined from independent sets of measurements and from back-analysis of the water retention curves of the OF and 6Cyc samples.

406 The air entry value of the microstructure was determined by introducing the value of the threshold pore radius separating the microstructure from the macrostructure in the Washburn-Laplace equation, which relates the pore size to the suction at which their desaturation takes place. Knowing the evolution of the air entry values and of $e_{m}$ and $e_{M}$ along the drying-wetting cycles (see Table 3) allowed calibrating $c_{m}$ and $c_{M}$ in eq. (13). For the tested soil, $c_{m}$ and $c_{M}$ were

410 found to be 16.5 and 4, respectively, as provided in Tables 4 . The parameters $n_{M}, m_{M}, n_{m}$, and $m_{m}$ of the van Genuchten 411 expression were calibrated upon the data of the first drying. The scanning parameter $k_{s c}$ was evaluated on the basis of 412 suction cycles run in a suction controlled oedometer (Azizi et al. 2017).

413 The compression behaviour of compacted samples of Viadana silt in saturated conditions presented in Nocilla et al. 414 (2006) was interpreted to determine $\lambda_{M}$ and $\kappa_{M}$, under the assumption that the volume strains of the microstructure can 415 be neglected if compared to those of the macrostructure. Data in the same work were also interpreted to determine the 416 slope $M$ of the critical state line in the $\left(p_{M}^{\prime}, q\right)$ plane, which was found to be $M=1.29$. The parameters $b_{1}$ and $b_{2}$ (eq. 417 (26)), describing hardening due to the macroscopic degree of saturation $S_{r M}$, and the parameters for the flow rule $\gamma$ and $418 d_{0}$ (eq. (30)), were calibrated on the results of the tests carried out on the OF samples, while they were used to predict 419 the behaviour of the 6Cyc samples. 
420

An oedometer test was performed to determine the preconsolidation stress, assuming that this was the same for the microstructure and the macrostructure. An OF specimen was compacted, saturated under a net axial stress $\sigma_{a x}^{n e t}=10 \mathrm{kPa}$ and then loaded. The axial preconsolidation stress was found to range about $\sigma_{a x}^{\prime *}=400 \mathrm{kPa}$. The radial stress at preconsolidation was estimated through Jaky's expression $K_{0}=1-\sin \varphi_{c s}^{\prime}$ (with $\varphi_{c s}^{\prime}$ as the critical state friction angle and $\sin \varphi_{c s}^{\prime}=\frac{3 M}{6+M}$ ), which provided $K_{0}=0.47$, giving $\sigma_{r}^{\prime *}=K_{0}{\sigma^{\prime}}_{a x}^{*} \cong 212 \mathrm{kPa}$. Eventually, the value of the mean preconsolidation stress in saturated conditions resulted in $p^{\prime *}=p_{M}^{\prime *}=p_{m}^{\prime *} \cong 360 \mathrm{kPa}$.

\subsection{Drying}

Drying took place in the suction - controlled triaxial cell, where target suction values $s_{0}=50 \mathrm{kPa}$ or $s_{0}=300 \mathrm{kPa}$ were imposed while keeping the mean net stress constant at $5 \mathrm{kPa}$ (stress path in Fig. 6a). The water ratio of all samples decreased as shown in Fig. 6b. When subjected to the same suction, 6Cyc samples expelled more water than OF samples. Figures $6 \mathrm{c}$ and $6 \mathrm{~d}$ show the experimental results and the model predictions for the OF and 6Cyc samples in terms of $e-e_{w}$. A small contraction occurred when imposing $s_{0}=300 \mathrm{kPa}$, but the effect of the suction increase was mostly a decrease of the total degree of saturation. At the end of the drying process the water ratio and degree of saturation of the 6Cyc samples was noticeably smaller than the one of the corresponding OF samples.

The main drying and wetting curves and the predictions of the evolution of the water ratio with suction are presented in Fig. 6e. The model allows explaining the different water ratios of the two samples at the end of drying. The hydraulic states of the OF samples were initially inside the reversible domain, very close to their main drying curve. Upon suction increase, they approached $\left(s_{0}=50 \mathrm{kPa}\right)$ or reached $\left(s_{0}=300 \mathrm{kPa}\right)$ the main drying curve. The $6 \mathrm{Cyc}$ samples were initially closer to their main wetting curve than the OF samples, since they had underwent wetting during the last preparatory stage. However, they also reached their main drying curve when subjected to increasing suction. According to eqs. $(10)$ and (12), the 6Cyc samples $\left(e_{M}=0.20\right)$ have a lower water retention capacity than OF samples $\left(e_{M}=0.17\right)$ because of their larger macrostructural void ratio-

\subsection{Isotropic Compression}

OF and 6Cyc samples were isotropically compressed to mean net stress values $p^{\text {net }}=100,200$ and $400 \mathrm{kPa}$ (samples with $s_{0}=50 \mathrm{kPa}$ ) or to a mean net stress value $p^{\text {net }}=100 \mathrm{kPa}$ (samples with $s_{0}=300 \mathrm{kPa}$ ) while keeping suction constant (Fig. 7a). At $p^{\text {net }}=100$ and $200 \mathrm{kPa}$, the 6Cyc samples were more compressible than the OF samples. However, the void ratios of the $\mathrm{OF}$ and of the $6 \mathrm{Cyc}$ samples were about the same at $p^{\text {net }}=400 \mathrm{kPa}$, which is consistent with the 
microstructural observations in Section 4. For both types of samples, the compressibility reduced with suction and axial stress.

The model provides very reasonable predictions of void ratio changes along isotropic compression, considering that the compressibility parameters of the macrostructure, $\kappa_{M}$ and $\lambda_{M}$, used in the simulations, were determined on different samples tested in saturated conditions. Also, the model correctly predicts that the void ratios of the 6Cyc samples are smaller than the void ratios of the OF samples at the same mean net stress, although this difference is overestimated at high stresses.

Figure 8a shows the changes in void and water ratios during isotropic compression. The water ratio decreased slightly in all cases, however, changes in the degree of saturation were negligible since the effects of changes in volume and water content counterbalanced each other. Figures $8 \mathrm{~b}$ and $8 \mathrm{c}$ show the results in terms of $e_{w}-s$. Because of the small decrease in the water ratio, the hydraulic states of all samples moved slightly towards the corresponding main wetting curve, still remaining rather close to the main drying curve. According to the model, both the main drying and the main wetting curves evolved due to the decrease of void ratios during isotropic compression, but the changes in the suction range of interest were very small (in the figure only the final position of the WRCs is shown).

\subsection{Triaxial compression}

468 Triaxial compression (shearing) at constant water content started from the conditions achieved after isotropic 469 compression. The experimental results and model predictions of the triaxial compression phase for the tests performed at a net confining stress of $100 \mathrm{kPa}\left(\mathrm{OF} \_1\right.$ and $6 \mathrm{Cyc} \_1$ with initial suction $s_{0}=50 \mathrm{kPa}$; OF_4 and 6Cyc_4 with initial suction $s_{0}=300 \mathrm{kPa}$ ) are plotted in Fig. 9. The peak strength and the post-peak softening of both OF and 6Cyc samples were larger at the highest suction (Fig. 9a). However, the 6Cyc samples showed a higher peak strength and a more pronounced softening than the OF samples when sheared at the same initial suction. The model predicts reasonably well the peak strength and the brittleness of these samples. Volumetric strains are plotted against deviatoric strains in Fig. 9b. All samples initially contracted and afterwards dilated. Dilatancy, which was larger in the case of the 6Cyc samples, increased with suction. The slope of volumetric strains changes with deviatoric strains, as predicted by the model in the plastic range (i.e. when the volume starts to increase), is quite similar to the experimental one, especially for the OF_4 and 6Cyc_4 samples. Suction decreased during all tests, more markedly the higher its initial value, and the decrease in suction was larger for the OF samples compared to the 6Cyc samples (Fig. 9c). Because of the constant water content 
condition, the total degree of saturation changed very slightly, increasing when the volume decreased and decreasing when the volume increased (Fig. 9d).

Figure 10 shows the results of the triaxial compression phase of the OF and 6Cyc samples confined at $200 \mathrm{kPa}$ and 400 $\mathrm{kPa}$ net stress and with an initial suction $s_{0}=50 \mathrm{kPa}$ (samples OF_2 and OF_3 and samples 6Cyc_2 and 6Cyc_3). At these higher confinement stresses, the deviatoric stress increased monotonically during triaxial compression, and the strength of the 6Cyc samples was slightly higher than the one of the OF samples (Fig. 10a). Monotonic compressive strains occurred in all tests (Fig. 10b) with the exception of 6Cyc_2 (the 6Cyc sample confined at $200 \mathrm{kPa}$ radial net stress), which showed moderate softening and little dilatancy. The decrease in suction experienced by the OF samples was larger than the one of the corresponding 6Cyc samples (Fig. 10c). Because of the constant water content constraint, and of contraction during triaxial compression, the total degree of saturation increased for all samples (Fig. 10d).

Figure 11 shows the evolution of suction during triaxial compression, together with the evolution predicted for the main drying and main wetting retention curves. For contracting samples, such as OF2 and 6Cyc_2 in Fig. 11a, the model predicts an increase of the water retention capacity, with the state of both samples remaining inside the reversible domain. On the contrary, for dilating samples such as $\mathrm{OF} \_4$ and 6Cyc_4 in Fig. 11b, the model predicts a decrease of the water retention capacity, and the final hydraulic state of these samples lays on the corresponding main drying curves.

\section{Discussion}

The model predictions can be exploited to provide an insight into the hydro-mechanical behaviour of the compacted Viadana silt.

At the end of the triaxial compression stage, the samples reached or approached (samples OF_1, OF_4 and 6Cyc_1) critical state conditions. Figure 12a compares the experimental points at the end of triaxial compression with the stress paths predicted by the model, together with results of undrained triaxial compression tests on saturated compacted samples from Nocilla et al. (2006), which are used to the sake of comparison. In the $\left(p_{M}^{\prime}, q\right)$ plane, the critical state for all the compacted samples (both saturated and unsaturated and regardless of the previous hydraulic history) is very well fitted with a single line having a slope $M=1.29$. This substantiates the use of the average skeleton stress as stress variable, which is made possible by the correct identification of the macro-structural degree of saturation. Also, the 
511 results in Fig. 12a validate the assumptions made on both the position of the threshold between the micro and the 512 macro-pores, and the coupled hydro-mechanical model governing the water retention behaviour of the two structural 513 domains.

515 The void ratio at critical state in Fig. 12b appears to be influenced by suction, as previously remarked for instance by 516 Gallipoli et al. (2003), suggesting that the locus of the critical state conditions should be fitted by a Critical State 517 Surface in the $\left(p_{M}^{\prime}, q, e, s\right)$ hyperspace rather than by a line in the traditional $\left(p_{M}^{\prime}, q, e\right)$ space. However, for given 518 suction, the OF and 6Cyc samples seem to approach the same line, suggesting that the Critical State Surface does not 519 depend substantially on the previous hydraulic history.

Figure 13 introduces the position of the yield curves of the macrostructure at the beginning of triaxial compression for the highly overconsolidated samples, tested at $100 \mathrm{kPa}$ confining stress (OF_1, OF_4 and 6Cyc_1, 6Cyc_4), together with the stress paths predicted by the model. All these samples dilated and softened. The preconsolidation pressure $p^{\prime}{ }_{0 M}$, which defines the size of the yield curves (eq. (25)), depends on the macrostructural degree of saturation $S_{r M}$ (eq. (26)): thus it increases with suction and, for the same suction, it is larger for the 6Cyc samples compared to the OF samples because of the reduced capacity to retain water of the former. This implies the sequence $p_{O M}^{\prime}\left(\mathrm{OF}_{-} 1\right)<p_{0 M}^{\prime}\left(6 \mathrm{Cyc} \_1\right)<$ $p^{\prime}{ }_{O M}\left(\mathrm{OF} \_4\right)<p^{\prime}{ }_{O M}\left(6 \mathrm{Cyc} \_4\right)$. The stress paths intercept the yield surface on the dry side, where $\eta_{M} / M>1$, and the model predicts negative $d$ values (which means volume increase, eq. (30)) for all of them. Since the hardening rule of the Modified Cam Clay is used, the interception between the stress paths and the yield surface provides the peak deviatoric stress, $q_{\text {peak }}$. Therefore, the larger the $p^{\prime}{ }_{0 M}$, the larger $q_{p e a k}$, which is consistent with the sequence of peak strengths detected in the experiments.

The stress paths of all the samples sheared at $200 \mathrm{kPa}$ and $400 \mathrm{kPa}$ confining stress and suction $s_{0}=50 \mathrm{kPa}$ intercepted the yield surface on the wet side $\left(\eta_{M} / M<1\right)$, which implied instead positive $d$ values, and then contraction and hardening. Figures $14 \mathrm{a}$ and $14 \mathrm{~b}$ show the experimental data and model predictions of the stress-dilatancy relationships for OF and 6Cyc samples, respectively. The state parameter of the samples sheared at $100 \mathrm{kPa}$ confining stress (OF_1, OF_4, 6Cyc_1 and 6Cyc_4) is negative, since their void ratios are smaller than the ones at critical state for the same stress conditions (see Fig. 12). These samples yield when $\eta_{M} / M>1$, with a predicted negative value of $d$ (hence, dilating). The opposite holds for the samples sheared at $200 \mathrm{kPa}$ and $400 \mathrm{kPa}$ of confining stress. Predictions compare very reasonably with the experimental data although the dilatancy of sample OF_4 appears to be underestimated. 
542 Relevant model predictions of the evolution of suction during triaxial compression are presented in Fig. 15. An air entry 543 value of the microstructure higher than $200 \mathrm{kPa}$ (Table 4) ensured that the microstructure remained saturated during all 544 the tests performed at $s_{0}=50 \mathrm{kPa}$. In these cases, the evolution of the WRC is governed by the changes occurring in the 545 macrostructure. An example is given by the OF_1 sample (Fig. 15a). At the beginning of triaxial compression, the 546 hydraulic state lays in the reversible domain. Here, according to eq. (11), suction decreases when the macrostructural 547 degree of saturation $S_{r M}$ increases and suction increases when $S_{r M}$ decreases. Along triaxial compression, an elastic 548 contraction occurs first, which in light of the constant water content constraint implies an increase in saturation and then 549 a decrease in suction. Afterwards, for $\varepsilon_{q}>0.02$, the sample dilates, thus $S_{r M}$ decreases and suction increases again. Note that this monotonous relationship between suction and volume changes occurs only because the hydraulic state always 551 moves within the reversible domain, and not on the main drying curves plotted as grey lines in Fig. 15a. Similarly, the 552 hydraulic state moved within the reversible domain also in the other samples tested at $s_{0}=50 \mathrm{kPa}$, for which suction 553 changes and volume strains had the opposite sign.

555 On the contrary, when $s_{0}=300 \mathrm{kPa}$ (as for test $\mathrm{OF}_{-} 4$ in Fig. 15a), very little water is held by the macrostructure. The 556 bimodal WRC is then dominated by the microstructure, which reduces its water retention capacity when the 557 microstructural void ratio decreases, and the value of suction associated to the given water content on the main branches 558 of the WRC reduces (eqs. (10) and (13)). Note that this occurs also along the whole triaxial compression process, 559 following eq. (21). As shearing progresses, the main drying curve reaches the hydraulic state of the sample when $\varepsilon_{q}=$ $560 \quad 0.02$, which constrains the evolution of suction for the rest of the test to the main drying curve.

\section{Conclusions}

The hydro-mechanical behaviour of a compacted clayey silt in unsaturated conditions, at the as-compacted state and after exposure to drying-wetting cycles, was investigated by means of laboratory tests and then interpreted with a coupled double-porosity elasto-plastic model. Drying-wetting cycles at low confinement stresses alter the soil fabric promoting volumetric shrinkage of the microstructure, made of clay peds, and a consequent increase of the macroporosity. This porosity exchange significantly reduces the capacity of the soil to retain water for values of suction smaller than about $400 \mathrm{kPa}$. Because of its larger macro-porosity, the dried-wetted soil is more compressible than the as-compacted soil when small loads are applied. The response to triaxial compression at constant water content 
572 conditions is also affected. At the same initial values of mean net stress and suction, the dried-wetted soil shows higher

573 shear strength and more brittle behaviour than the 'as-compacted' soil. This is a consequence of different effects of the 574 fabric changes induced by the previous drying-wetting cycles. Firstly, because of the differences in the water retention 575 behaviour, the suction decrease occurring during triaxial compression is more contained in the dried-wetted material 576 compared to the as-compacted one, which keeps the stress path on a drier side. Secondly, higher suction implies higher 577 dilatancy, hence, higher peak strength.

579 The proposed elasto-plastic coupled hydro-mechanical double porosity framework allowed reproducing all the relevant 580 aspects observed during the tests. The model, which adopts the average skeleton stress of the macrostructure as a 581 constitutive stress for the macro-porosity domain, permits a natural transition from saturated to unsaturated conditions. 582 The slope of the critical state line in the mean - deviatoric stress plane is clearly the same for the saturated and 583 unsaturated conditions, and for any of the two fabrics of the unsaturated material, although the void ratio at critical state 584 depends on the suction. The volumetric and hydraulic behaviour along isotropic compression in unsaturated conditions 585 is reasonably reproduced using the elastic and elasto-plastic compliance parameters deduced from tests on saturated 586 samples to characterize the behaviour of the macrostructure.

588 The mechanical behaviour of the macrostructure is nicely captured with an elasto-plastic model which adopts the yield 589 surface of the Modified Cam Clay, where the preconsolidation pressure increases when the degree of saturation 590 decreases. The different response to triaxial compression is triggered by the different water retention behaviour for the 591 two fabrics. Since preliminary drying-wetting cycles reduce the volume the water retention capacity of the macro592 structure, the higher peak strength of the dried-wetted samples can be explained accounting for their smaller macro593 structural degree of saturation, which implies a larger preconsolidation pressure. A non-associated flow rule, which 594 takes into account the role of the state parameter, of the degree of saturation of macropores and of suction, further contributes to nicely reproducing the increasing dilatancy and higher peak strength of the dried-wetted samples. 


\section{References}

599 Alonso, E.E., Pereira, J.M., Vaunat, J. and Olivella, S. 2010. A microstructurally based effective stress for unsaturated 600 soils. Géotechnique, 60(12), 913-925.

601 Alonso, E.E., Romero E. and Ortega, E. 2016. Yielding of rockfill in relative humidity-controlled triaxial experiments. 602 Acta Geotechnica, 11, 455-477. doi:10.1007/s11440-016-0437-9.

603 Alonso, E.E., Vaunat, J. and Gens, A. 1999. Modelling the mechanical behaviour of expansive clays. Engineering 604 Geology 54, 173-183.

Azizi, A., Jommi, C. and Musso, G. 2017. A water retention model accounting for the hysteresis induced by hydraulic and mechanical wetting-drying cycles. Computers and Geotechnics, 87, 86-98.

Azizi, A., Musso, G. and Jommi, C. 2019. Effects of repeated hydraulic loads on microstructure and hydraulic behaviour of a compacted clayey silt. Canadian Geotechnical Journal, Accepted.

Barenblatt, G.I., Zheltov, Iu.P. and Kochina, I.N. 1960. Basic concepts in the theory of seepage of homogeneous liquids in fissured rocks. J. Appl. Math. Mech., 24(5), 1286-1303.

Been, K. and Jefferies, M.G. 1985. A state parameter for sands. Géotechnique, 35(2), 99-112.

Benson, C.H., Sawangsuriya, A., Trzebiatowski, B. and Albright, W.H. 2007. Postconstruction changes in the hydraulic properties of water balance cover soils. Journal of Geotechnical and Geoenvironmental Engineering, 133(4), 349-359.

Blight, G.E. 1964. The Effect of non-uniform pore pressure on laboratory measurements of the shear strength of soils. ASTM symposium on laboratory shear testing of soils, STP 361, 173-191.

619 Casini, F., Vaunat, J., Romero, E. and Desideri, A. 2012. Consequences on water retention properties of double-porosity

Calabresi, G., Colleselli, F., Danese, D., Giani, G. P., Mancuso, C., Montrasio, L., Nocilla, A., Pagano, L., Reali, E. and Sciotti A. 2013. A research study of the hydraulic behaviour of the Po river embankments. Canadian Geotechnical Journal, 50, 9, 947-960. features in a compacted silt. Acta Geotechnica, 7(2), 139-150.

Cattoni, E., Cecconi, M and Jommi, C. 2005. Soil dilatancy and suction: some remarks on their mutual effect on the on the shear strength of granular soils. In: Proceedings of the eleventh international conference on computers methods and advances in geomechanics, Torino, Italy, pp 19-26.

Chiu, C.F. and Ng, C.W.W. 2003. A state-dependent elasto-plastic model for saturated and unsaturated soils Géotechnique, 53, No. 9, 809-829.

626 Choo, J., White, A.J. and Borja, R.I. 2016. Hydromechanical Modeling of Unsaturated Flow in Double Porosity Media. Int. J. Geomech., D4016002. doi:10.1061/(ASCE) GM.1943-5622.0000558.

Cui, Y. and Delage, P. 1996. Yielding and plastic behaviour of an unsaturated compacted silt. Géotechnique, 46(2):291-311.

Cuisinier, O. and Laloui, L. 2004. Fabric evolution during hydromechanical loading of a compacted silt. Int. J. Numer.

Delage, P. and Lefebvre, G. 1984. Study of the structure of a sensitive Champlain clay and its evolution during consolidation. Canadian Geotechnical Journal; 21:21-35.

Delage, P. and Pellerin, F.M. 1984. Influence de la lyophilisation sur la structure d'une argile sensible du Québec. Clay

Della Vecchia, G., Dieudonne, A.C., Jommi, C. and Charlier, R. 2015. Accounting for evolving pore size distribution in water retention models for compacted clays. International Journal for Numerical and Analytical Methods in Geomechanics, 39 (7), 702-723. 
641 Durner, W. 1994. Hydraulic conductivity estimation for soils with heterogeneous pore structure. Water Resources 642 Research, 30(2), 211-223.

643 Fern, E.J., Robert, D.J., and Soga, K. 2016. Modeling the Stress-Dilatancy Relationship of Unsaturated Silica Sand in 644 Triaxial Compression Tests. J. Geotech. Geoenviron. Eng., 142(11): 04016055.

645 Gallipoli, D., Gens, A., Sharma, R., and Vaunat, J. 2003.An elasto-plastic model for unsaturated soil incorporating the 646 effects of suction and degree of saturation on mechanical behaviour. Géotechnique, 53(1), 123- 135.

Gens, A. and Alonso, E.E. 1992. A framework for the behaviour of unsaturated expansive clays. Canadian Geotechnical Journal, 29:1013-1032, https://doi.org/10.1139/t92-120.

Gerke, H.H. and van Genuchten, M.T. 1993. A dual-porosity model for simulating the preferential movement of water and solutes in structured porous media. Water Resour. Res., 29(2), 305-319.

Jommi, C. 2000. Remarks on the constitutive modelling of unsaturated soils, in Proc. Int. Workshop on Unsaturated 653 Soils: Experimental Evidence and Theoretical Approaches in Unsaturated Soils, edited by A. Tarantino and C. Mancuso, pp. 139-153, A.A. Balkema, Rotterdam, Netherlands.

Kemal, S., Kiyama, S., Aoyama, S. and Kobayashi A. 2005. Laboratory Study on Shear Behavior of Unsaturated Granular Soil During Cyclic Suction Loading. Transactions of The Japanese Society of Irrigation, Drainage and Reclamation Engineering, 2005, 238, 329-335.

Kim, B.S., Park S.W., Takeshita Y. and Kato S. 2016. Effect of suction stress on critical state of compacted silty soils under low confining pressure. Int. J. Of Geomechanics, 16 (6): D4016010.

Kohgo, Y., Nakano, M. and Mihazaki, T. 1993. Theoretical aspects of constitutive modelling for unsaturated soils. Soils and Foundations 33, 4, 49-63. doi.org/10.3208/sandf1972.33.4_49.

Kovacevic, N., Potts, D.M. and Vaughan, P.R. 2001. Progressive failure in clay embankments due to seasonal climate changes. Proc. 15th Int. Conf. Soil Mech. Geotech. Engng, Istanbul, Turkey 3, 2127-2130.

Ma, T., Wei, C., Wei, H. and Li, W. 2016. Hydraulic and Mechanical Behavior of Unsaturated Silt: Experimental and Theoretical Characterization. Int. J. Geomech., 16(6): D4015007.

Mašín, D. 2013. Double structure hydromechanical coupling formalism and a model for unsaturated expansive clays. Engineering Geology, 165: 73-88.

Monroy, R., Zdravkovic, L. and Ridley, A. 2010. Evolution of microstructure in compacted London Clay during wetting and loading, Géotechnique 60, 2, 105-119, doi: 10.1680/geot.8.P.125.

Musso, G., Romero, E. and Della Vecchia, G. 2013. Double-structure effects on the chemo-hydro-mechanical behaviour of a compacted active clay. Géotechnique, 63(3), 206-220.

Ng, C.W.W., Mu, Q.Y. and Zhou, C. 2017. Effects of soil structure on the shear behaviour of an unsaturated loess at different suctions and temperatures. Can. Geotech. J. 54: 270-279.

684 Romero, E. 1999. Thermo-hydro-mechanical behaviour of unsaturated Boom clay: an experimental study. PhD thesis,

Nocilla, A., Coop, M.R. and Colleselli, F. 2006. The mechanics of an Italian silt: an example of "transitional" behaviour. Géotechnique 56, 4, 261-271.

Nyambayo, V.P., Potts, D.M. and Addenbrooke, T.I. 2004. The influence of permeability on the stability of embankments experiencing seasonal cyclic pore water pressure changes. Advances in Geotechnical Engineering: Proceedings of the Skempton Conference (Jardine R. J., Potts D. M. and Higgins K. G. (eds)). Thomas Telford, London, 2004, 2, 898-910.

Rojas, J.C, Mancuso, C. and Danese, D. 2010. Pre and post-construction characterization of an embankment fill material. In "Unsaturated soils. Experimental studies in unsaturated soils and expansive soils". Proceedings of the 4th Asia Pacific conference on unsaturated soils, Newcastle, Australia, 23-25 November 2009. Buzzi O. Fytus S. and Sheng D. editors, CRC press. 
686
Romero, E. and Jommi, C. 2008. An insight into the role of hydraulic history on the volume changes of anisotropic clayey soils. Water Resources Research, 44, W12412, doi:10.1029/2007WR006558.

Romero, E., Vaunat, J. and Merchan, V. 2014. Suction effects on the residual shear strength of clays. Journal of GeoEngineering Sciences 2 (2014) 17-37, doi:10.3233/JGS-141320.

Roscoe, K.H. and Burland, J.B. 1968. Engineering Plasticity, Cambridge University Press, Evanston, IL, p. 535, J. Heyman, F.A. Leckie (Eds.).

Rouainia, M., Davies, O. O’Brien, T. and Glendinning, S. 2009. Numerical modelling of climate effects on slope stability. Proceedings of the Institution of Civil Engineers - Engineering Sustainability, 162, 2, 81-89.

Take, W.A. and Bolton, M.D. 2011. Seasonal ratcheting and softening in clay slopes, leading to first-time failure. Géotechnique 61, 9, 757-769.

Tamagnini, R. 2004. An extended Cam-clay model for unsaturated soils with hydraulic hysteresis. Géotechnique 54, 3, 223-28.

Van Genuchten, M.T. 1980. A closed-form equation for predicting the hydraulic conductivity of unsaturated soils. Soil Science Society of America Journal, 44, 892-898.

Vassallo, R., Mancuso, C. and Vinale, F. 2007. Effects of net stress and suction history on the small strain stiffness of a compacted clayey silt. Canadian Geotechnical Journal, 44(4), 447-462.

Warren, J. and Root, P. 1963. The behavior of naturally fractured reservoirs. SPEJ.,3(3),245-255.

Yao, Y.P., Niu, L. and Cui, W.J. 2014. Unified hardening (UH) model for overconsolidated unsaturated soils. Canadian Geotechnical Journal, 51:810-821 https://doi.org/10.1139/cgj-2013-0183.

Zhan, T.L.T. and Ng, C.W.W. 2006. Shear strength characteristics of an unsaturated expansive clay. Canadian Geotechnical Journal, 43(7): 751-763. doi:10.1139/t06-036.

Zhang, F. and Ikariya T. 2011. A new model for unsaturated soil using skeleton stress and degree of saturation as state variables. Soils and foundations. 51 (1), 67-81.

Zhang, J., Sun, D., Zhou, A. and Jiang, T. 2016. Hydromechanical behaviour of expansive soils with different suctions and suction histories. Canadian Geotechnical Journal, 53:1-13, https://doi.org/10.1139/cgj-2014-0366.

Zhou, A.N. and Sheng, D. 2015. An advanced hydro-mechanical constitutive model for unsaturated soils with different initial densities. Computers and Geotechnics, 63, 46-66, doi.org/10.1016/j.compgeo.2014.07.017.

Zhou, A.N., Sheng, D., Sloan, S.W. and Gens, A. 2012. Interpretation of unsaturated soil behaviour in the stresssaturation space: II: Constitutive relationships and validations. Computers and Geotechnics, 43, 111-123 https://doi.org/10.1016/j.compgeo.2012.02.009. 


\section{$727 \quad$ List of symbols}

$728 \quad$ Void ratio: $e$

729 Microscopic void ratio: $e_{m}$

730 Macroscopic void ratio: $e_{M}$

731 Degree of saturation: $S_{r}$

732 Microscopic degree of saturation: $S_{r m}$

733 Macroscopic degree of saturation: $S_{r M}$

734 Water ratio: $e_{w}$

735 Water ratio of the microstructure: $e_{w m}$

736 Water ratio of the macrostructure: $e_{w M}$

737 Initial value of air entry pressure of the microstructure: $1 / \alpha_{m 0}$

738 Initial value of the air entry pressure of the macrostructure: $1 / \alpha_{M 0}$

739 Parameters of the van Genuchten expression of the microstructure: $n_{m}$ and $m_{m}$

740 Parameters of the van Genuchten expression of the macrostructure: $n_{m}$ and $m_{m}$

741 Model parameter controlling the dependency of microstructure on air entry value: $c_{l}$

742 Model parameter controlling the dependency of macrostructure on air entry value: $c_{2}$

743 Skeleton stress of the microstructure: $\sigma_{\mathrm{m}}^{\prime}$

744 Skeleton stress of the macrostructure: $\sigma_{M}{ }_{M}$

745 Preconsolidation stress of the microstructure: $p^{*}{ }_{0 m}$

746 Saturated preconsolidation stress of the macrostructure: $p^{*}{ }_{0 M}$

747 Suction increase of the microstructure: $s_{I}$

748 Suction decrease of the microstructure: $s_{D}$

749 Slope of the critical state line in the $\left(\mathrm{p}^{\prime}{ }_{\mathrm{M}}, \mathrm{q}\right)$ plane: $M$

750 Elastic logarithmic compliance of the microstructure: $\kappa_{m}$

751 Elastic logarithmic compliance of the macrostructure: $\kappa_{M}$

752 Elasto-plastic logarithmic compliance of the macrostructure: $\lambda_{m}$

753 Elasto-plastic logarithmic compliance of the macrostructure: $\lambda_{M}$

754 Poisson coefficient of the macrostructure: $v$

755 Parameters of the modified Li and Dafalias flow rule: $d_{0}, \gamma, m$ 


\section{List of Tables}

765 Table 1. State of the samples for MIP analyses

766 Table 2. Samples for hydro-mechanical characterization with values of suction and isotropic net stress applied during 767 isotropic compression in the triaxial tests

768 Table 3. Macro-structural, micro-structural and total void ratios from interpretation of MIP analyses

769 Table 4. Values of the parameters used in the numerical simulations

770

771

772

773

774

775

776

777

778

779

780

781

782

783

784

785

786

787 


\section{List of Figures}

789 Fig. 1. SEM images of OF sample: (a) detail with macropores, clay peds and silt particles; (b) detail with micropores within a clay ped.

791 Fig. 2. Hydraulic and mechanical histories of samples prepared for MIP analysis.

792 Fig. 3. Volumetric strains during the drying-wetting cycles. Positive volume strains indicate volume decrease, negative 793 volume strains indicate volume increase.

794 Fig. 4. Evolution of the PSD with drying-wetting cycles and with mechanical loading: (a) evolving the PSD with drying and wetting; (b) evolving the PSD of OF samples with mechanical loading; (c) evolving the PSD of 6Cyc samples with mechanical loading; (b) the PSDs of OF and 6Cyc samples being subjected to 1.6 MPa.

Fig. 5. Evolution of void ratio $e$, micro-structural void ratio $e_{m}$ and macro-structural void ratio $e_{M}$ : (a) with hydraulic loads; (b) with mechanical loads.

799 Fig. 6. Behaviour of samples along drying to 50 and $300 \mathrm{kPa}$ of suction: a) stress and hydraulic paths; b) evolution of water ratio with time; c) void ratio-water ratio OF samples; d) void ratio-water ratio 6Cyc samples; e) suction- water ratio.

802 Fig. 7. Isotropic compression at mean net stress $p^{\text {net }}=100,200$ and $400 \mathrm{kPa}$; a) stress path; b) void ratio- mean net stress.

804 Fig. 8. Behaviour of OF and 6Cyc samples along isotropic compression to mean net stress of $p^{\text {net }}=100,200$ and 400 $805 \mathrm{kPa}$ a) void ratio-water ratio; b) suction-water ratio.

806 Fig. 9. Behaviour of OF and 6Cyc samples $\left(s_{0}=50\right.$ and $\left.300 \mathrm{kPa}, p^{\text {net }}=100 \mathrm{kPa}\right)$ along triaxial compression at constant 807 water content: a) deviatoric stress - deviatoric strains; b) volume strain - deviatoric strain; c) suction - deviatoric strain; 808 d) degree of saturation - deviatoric strain.

809 Fig. 10. Behaviour OF and 6Cyc samples ( $s_{0}=50 \mathrm{kPa}, p^{\text {net }}=200 \mathrm{kPa}$ and $\left.400 \mathrm{kPa}\right)$ along triaxial compression at 810 constant water content: a) deviatoric stress - deviatoric strains; b) volume strain - deviatoric strain; c) suction 811 deviatoric strain; d) degree of saturation - deviatoric strain.

812 Fig. 11. Behaviour of OF and 6Cyc samples $\left(s_{0}=50 \mathrm{kPa}\right.$ and $s_{0}=300 \mathrm{kPa}, p_{\text {net }}=100,200$ and $\left.400 \mathrm{kPa}\right)$ during the 813 triaxial compression phase: (a) void ratio-water ratio for samples with $s_{0}=50 \mathrm{kPa}$; b) suction-water ratio for samples 814 with $s_{0}=300 \mathrm{kPa}$.

815 Fig. 12. Interpretation of final testing conditions and model predictions in terms of macroscopic average skeleton stress 816 of the macrostructure: (a) deviatoric - mean stress plane; (b) compression plane.

817 Fig. 13. Stress paths and initial position of the yield curve: (a) OF_1 and 6Cyc_1 ( $s_{0}=50 \mathrm{kPa}$ ); (b) samples OF_4 and 818 6Cyc_4 $\left(s_{0}=300 \mathrm{kPa}\right)$.

819 Fig. 14. Relationship between stress ratio and dilatancy: (a) OF samples; (b) 6Cyc samples.

820 Fig. 15. Changes in suction and evolution of the points lying on the main drying and main wetting curves: (a) test OF_1 $\left(s_{0}=50 \mathrm{kPa}\right) ;(\mathrm{b}) \mathrm{OF}_{-} 4\left(s_{0}=300 \mathrm{kPa}\right)$. 
Table 1. State of the samples for MIP analyses.

\begin{tabular}{|c|c|c|c|c|c|}
\hline Sample & $\begin{array}{c}\text { Axial stress } \\
\sigma_{a x}(\mathrm{kPa})\end{array}$ & Hydraulic state & $\begin{array}{c}\text { Void ratio } \\
e(-)\end{array}$ & $\begin{array}{c}\text { Water content } \\
w(\%)\end{array}$ & $\begin{array}{c}\text { Degree of } \\
\text { saturation } S_{r} \\
(-)\end{array}$ \\
\hline OF & - & - & 0.66 & 20.0 & 0.83 \\
\hline dry- OF & - & $\begin{array}{c}\text { Dry } \\
\text { (first drying) }\end{array}$ & 0.64 & 1.8 & 0.08 \\
\hline dry-6Cyc & - & $\begin{array}{c}\text { Dry } \\
\text { (6th drying) }\end{array}$ & 0.63 & 0.4 & 0.07 \\
\hline 6Cyc & - & $\begin{array}{c}\text { Wet } \\
6^{\text {th }} \text { drying- } \\
\text { wetting cycle) }\end{array}$ & 0.65 & 19.9 & 0.83 \\
\hline LL-OF & 98 & - & 0.61 & 18.9 & 0.85 \\
\hline HL-OF & 1600 & - & 0.51 & 18.5 & 0.93 \\
\hline LL-6Cyc & 98 & $\begin{array}{c}\text { Wet } \\
6^{\text {th }} \text { drying- } \\
\text { wetting cycles }\end{array}$ & 0.59 & 18.2 & 0.86 \\
\hline HL-6Cyc & 1600 & $\begin{array}{c}\text { Wet } \\
6^{\text {th }} \text { drying- } \\
\text { wetting cycles }\end{array}$ & 0.51 & 17.5 & 0.95 \\
\hline
\end{tabular}

Table 2. Samples for hydro-mechanical characterization with values of suction $s$ and mean net stress $p^{\text {net }}$ applied during drying and isotropic compression in the triaxial tests

\begin{tabular}{|c|c|c|c|c|}
\hline \multirow{2}{*}{ Test } & \multicolumn{2}{|c|}{ Drying } & \multicolumn{2}{c|}{ Isotropic compression } \\
\cline { 2 - 5 } & $\begin{array}{c}\text { Suction, } \\
s(\mathrm{kPa})\end{array}$ & $\begin{array}{c}\text { Mean net stress } \\
p^{\text {net }},(\mathrm{kPa})\end{array}$ & $\begin{array}{c}\text { Suction, } \\
s(\mathrm{kPa})\end{array}$ & $\begin{array}{c}\text { Mean net stress } \\
p^{\text {net }},(\mathrm{kPa})\end{array}$ \\
\hline OF_1 & 50 & $5-10$ & 50 & 100 \\
\hline OF_2 & 50 & $5-10$ & 50 & 200 \\
\hline OF_3 & 50 & $5-10$ & 50 & 400 \\
\hline OF_4 & 300 & $5-10$ & 300 & 100 \\
\hline 6Cyc_1 & 50 & $5-10$ & 50 & 100 \\
\hline 6Cyc_2 & 50 & $5-10$ & 50 & 200 \\
\hline 6Cyc_3 & 50 & $5-10$ & 50 & 400 \\
\hline 6Cyc_4 & 300 & $5-10$ & 300 & 100 \\
\hline
\end{tabular}


Table 3. Macro-structural, micro-structural and overall void ratios from interpretation of MIP analyses

\begin{tabular}{|c|c|c|c|c|c|c|c|c|}
\hline \multirow{2}{*}{ Void ratio } & \multirow{2}{*}{ OF } & \multicolumn{3}{|c|}{ Subjected to hydraulic load } & \multicolumn{2}{c|}{ Subjected to mechanical load } & \multicolumn{2}{c|}{$\begin{array}{c}\text { Subjected to hydraulic } \\
\text { and mechanical load }\end{array}$} \\
\cline { 3 - 9 } & & dry-OF & dry-6Cyc & 6Cyc & LL-OF & HL-OF & LL-6Cyc & HL-6Cyc \\
\hline$e$ & 0.66 & 0.63 & 0.63 & 0.66 & 0.61 & 0.51 & 0.59 & 0.51 \\
\hline$e_{m}$ & 0.42 & 0.41 & 0.38 & 0.38 & 0.44 & 0.42 & 0.40 & 0.41 \\
\hline$e_{M}$ & 0.17 & 0.16 & 0.18 & 0.20 & 0.12 & 0.06 & 0.14 & 0.07 \\
\hline
\end{tabular}

Table 4. Values of the parameters used in the numerical simulations

\begin{tabular}{|c|c|c|c|c|c|c|c|c|c|c|c|}
\hline \multicolumn{12}{|c|}{ Hydraulic Parameters } \\
\hline \multirow[b]{2}{*}{$\begin{array}{l}\text { Hydraulic } \\
\text { path }\end{array}$} & \multicolumn{4}{|c|}{ Micro-structure } & \multicolumn{5}{|c|}{ Macro-structure } & \multirow{2}{*}{\multicolumn{2}{|c|}{$\begin{array}{c}\begin{array}{l}\text { Both } \\
\text { domains }\end{array} \\
\begin{array}{c}\mathrm{k}_{\mathrm{sc}} \\
\left(\mathrm{kPa}^{-1}\right)\end{array} \\
\end{array}$}} \\
\hline & $\begin{array}{l}1 / \alpha_{\mathrm{m} 0} \\
(\mathrm{kPa})\end{array}$ & $\begin{array}{l}\mathrm{n}_{\mathrm{m}} \\
(-)\end{array}$ & $\begin{array}{c}\mathrm{m}_{\mathrm{m}} \\
(-)\end{array}$ & $\begin{array}{l}\mathrm{c}_{\mathrm{m}} \\
(-)\end{array}$ & \multicolumn{2}{|c|}{$\begin{array}{l}1 / \alpha_{\mathrm{M} 0} \\
(\mathrm{kPa})\end{array}$} & $\begin{array}{l}\mathrm{n}_{\mathrm{M}} \\
(-)\end{array}$ & $\begin{array}{c}\mathrm{m}_{\mathrm{M}} \\
(-)\end{array}$ & $\begin{array}{l}\mathrm{c}_{\mathrm{M}} \\
(-)\end{array}$ & & \\
\hline Drying & 236 & 2.86 & 0.14 & \multirow{2}{*}{16.5} & \multicolumn{2}{|c|}{64} & 1.75 & 0.83 & 4 & \multirow{2}{*}{\multicolumn{2}{|c|}{$3 \cdot 10^{-4}$}} \\
\hline Wetting & 34 & 2.61 & 0.12 & & \multicolumn{2}{|c|}{8} & 2.37 & 0.97 & & & \\
\hline \multicolumn{12}{|c|}{ Mechanical Parameters, Micro-structure } \\
\hline $\begin{array}{l}\kappa_{\mathrm{m}} \\
(-)\end{array}$ & $\begin{array}{l}\lambda_{\mathrm{m}} \\
(-) \\
\end{array}$ & $\begin{array}{l}\mathrm{h}_{1 \mathrm{C}} \\
(-)\end{array}$ & \multicolumn{2}{|c|}{$\begin{array}{l}\mathrm{h}_{\mathrm{s}} \\
(-)\end{array}$} & \multicolumn{2}{|c|}{$\begin{array}{l}\mathrm{p}^{\prime *}{ }_{\mathrm{m}} \\
(\mathrm{kPa})\end{array}$} & $\begin{array}{c}\mathrm{S}_{\mathrm{I}} \\
(\mathrm{kPa})\end{array}$ & \multicolumn{4}{|c|}{$\begin{array}{c}\mathrm{S}_{\mathrm{D}} \\
(\mathrm{kPa})\end{array}$} \\
\hline 0.009 & 0.056 & 4.3 & \multicolumn{2}{|c|}{0.25} & \multicolumn{2}{|c|}{360} & 236 & \multicolumn{4}{|c|}{$\begin{array}{l}33 \text { (OF) } \\
5 \text { (6Сус) }\end{array}$} \\
\hline \multicolumn{12}{|c|}{ Mechanical Parameters, Macro-structure } \\
\hline $\begin{array}{l}\kappa_{\mathrm{M}} \\
(-)\end{array}$ & $\begin{array}{c}v \\
(-)\end{array}$ & $\begin{array}{l}\lambda_{\mathrm{M}} \\
(-)\end{array}$ & \multicolumn{2}{|c|}{$\begin{array}{l}\mathrm{p}^{\prime *}{ }_{\mathrm{M}} \\
(\mathrm{kPa})\end{array}$} & $\begin{array}{l}b_{1} \\
(-)\end{array}$ & $\begin{array}{l}\mathrm{b}_{2} \\
(-)\end{array}$ & $\begin{array}{l}M \\
(-)\end{array}$ & $\begin{array}{l}\mathrm{d}_{0} \\
(-)\end{array}$ & \multicolumn{2}{|c|}{$\begin{array}{c}\gamma \\
\left(\mathrm{kPa}^{-1}\right)\end{array}$} & $\begin{array}{l}\mathrm{m} \\
(-)\end{array}$ \\
\hline 0.025 & 0.2 & 0.13 & \multicolumn{2}{|c|}{360} & 0.14 & 2.2 & 1.29 & 1.7 & \multicolumn{2}{|c|}{0.03} & 1.2 \\
\hline
\end{tabular}




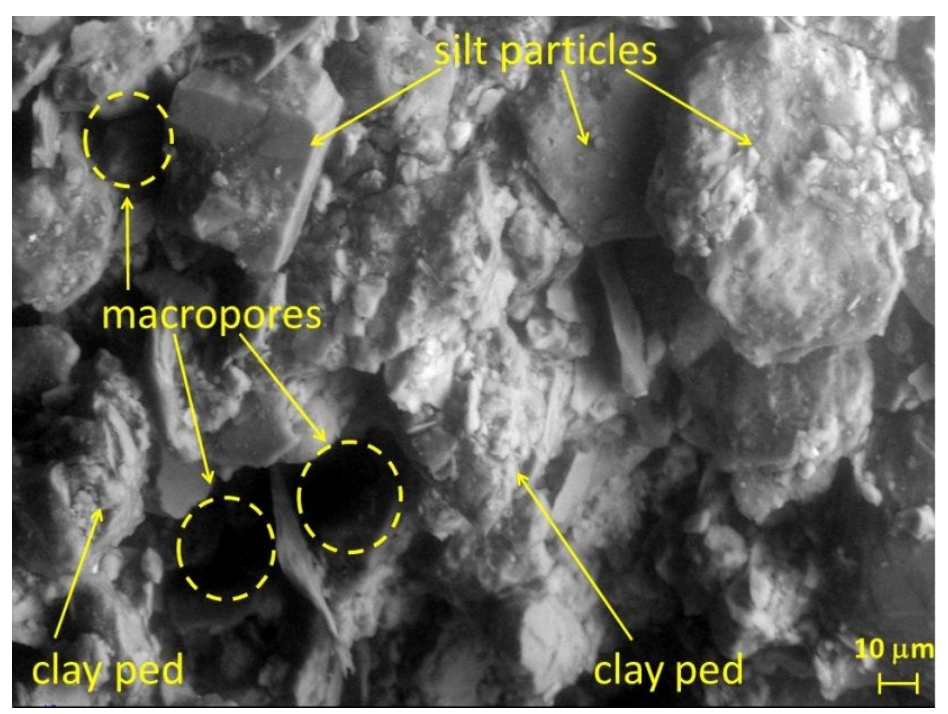

(a)

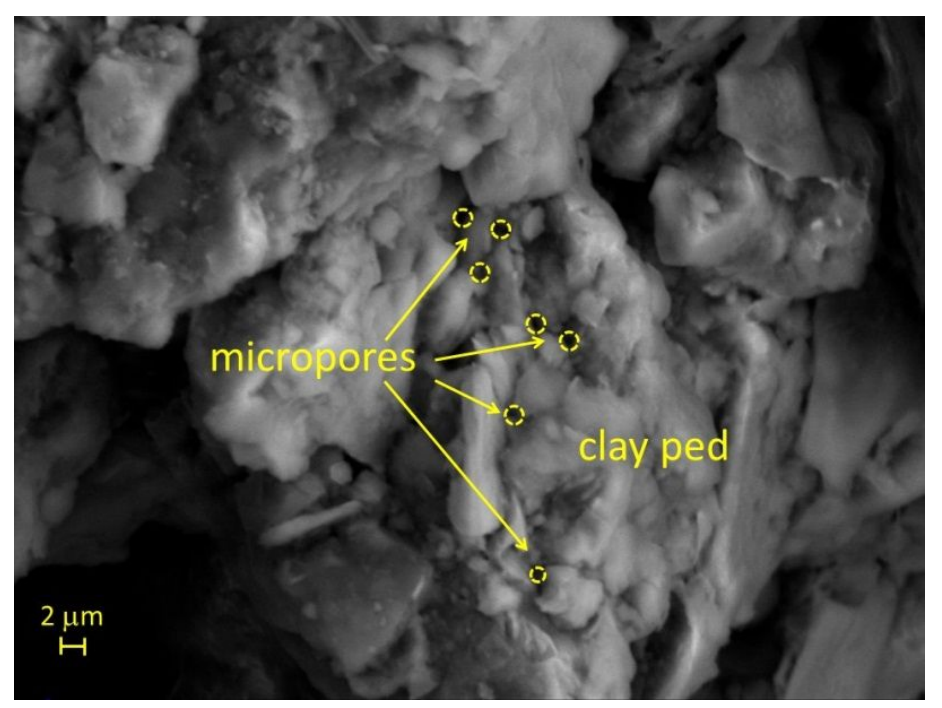

(b)

Fig. 1. SEM images of OF sample: (a) detail with macropores, clay peds and silt particles; (b) detail with micropores within a clay ped. 


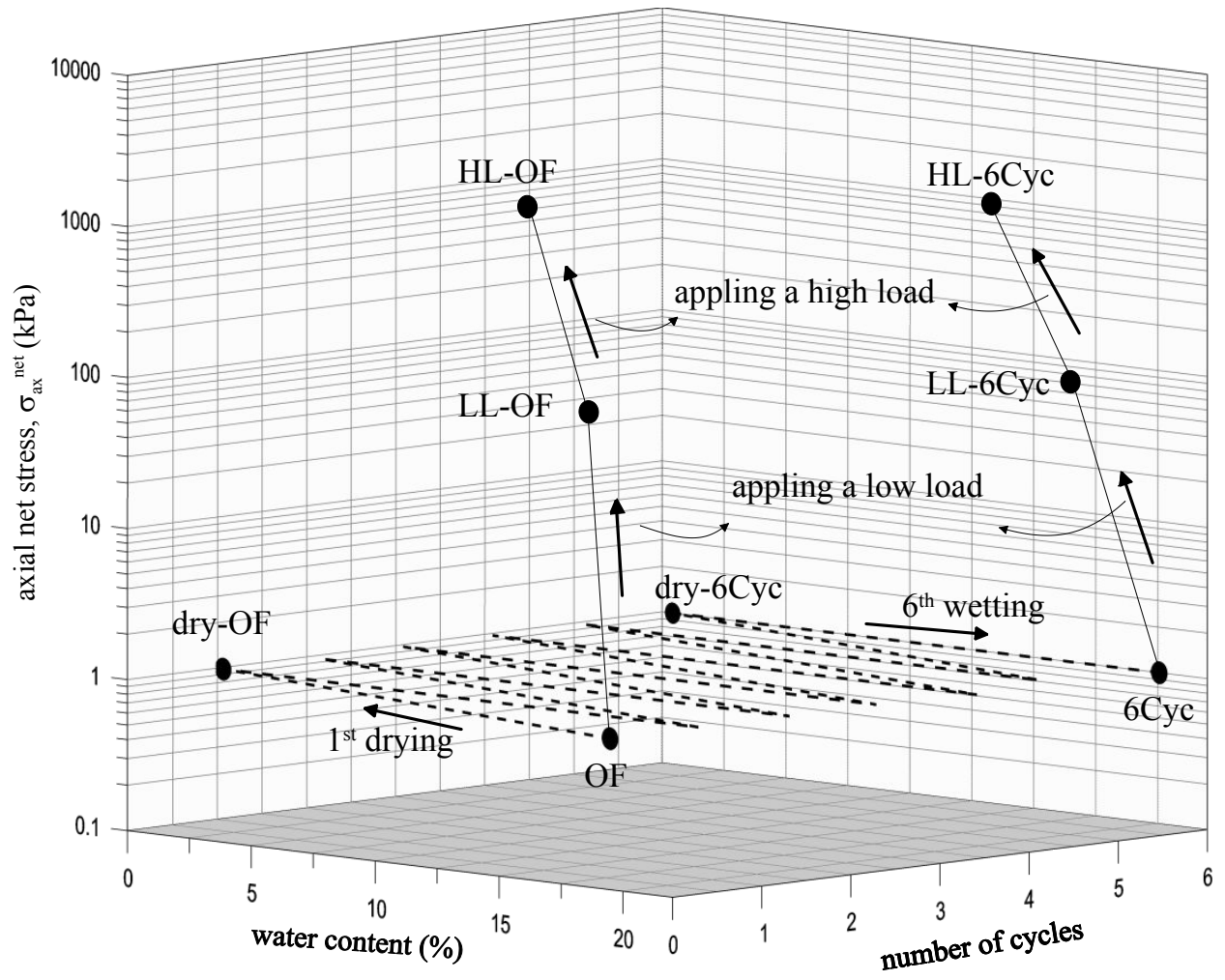

Fig. 2. Hydraulic and mechanical histories of samples prepared for MIP analysis. 


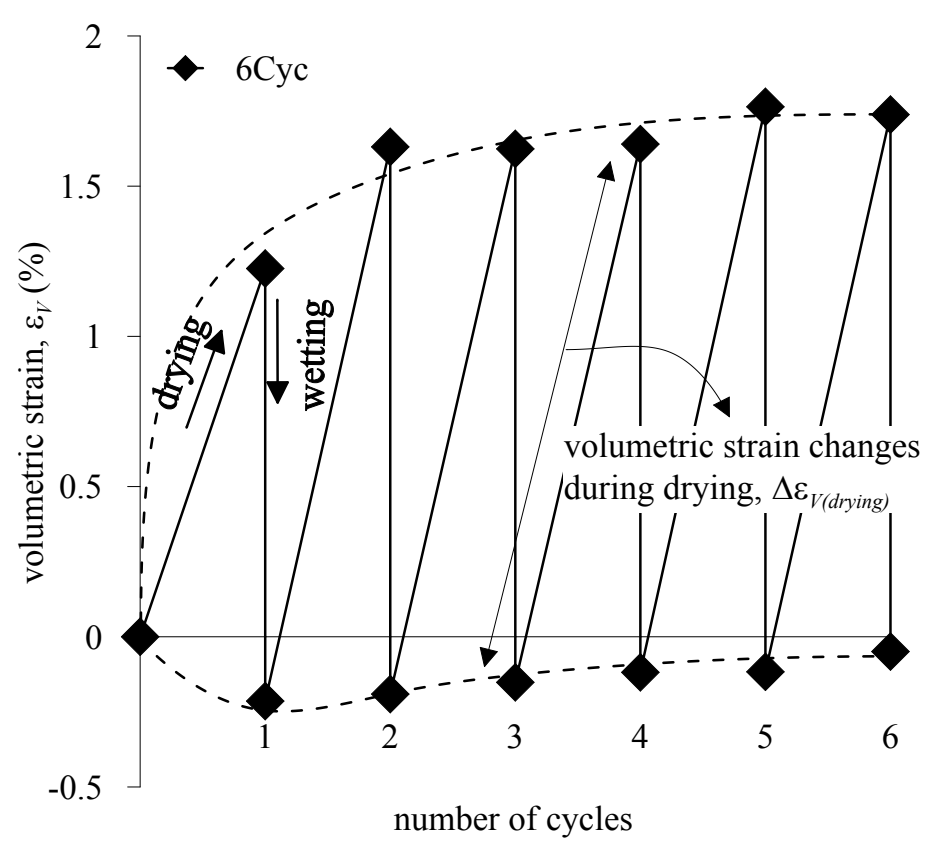

Fig. 3. Volumetric strains during the drying-wetting cycles. Positive volume strains indicate volume decrease, negative volume strains indicate volume increase. 


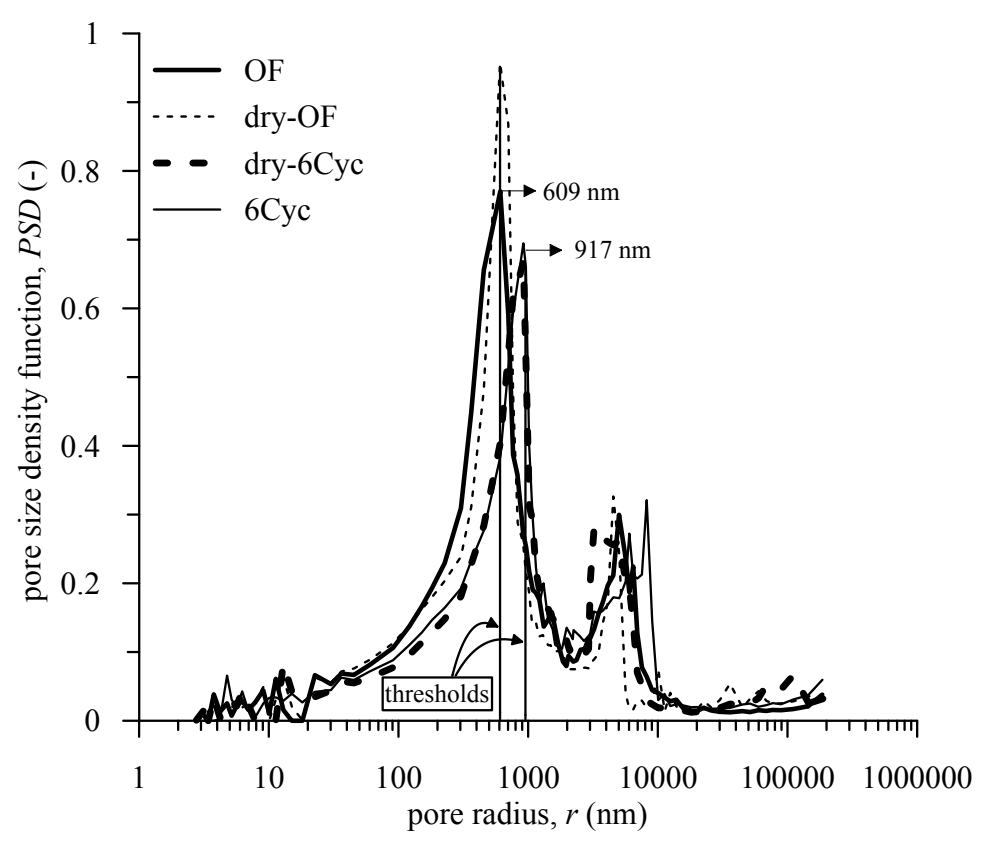

(a)

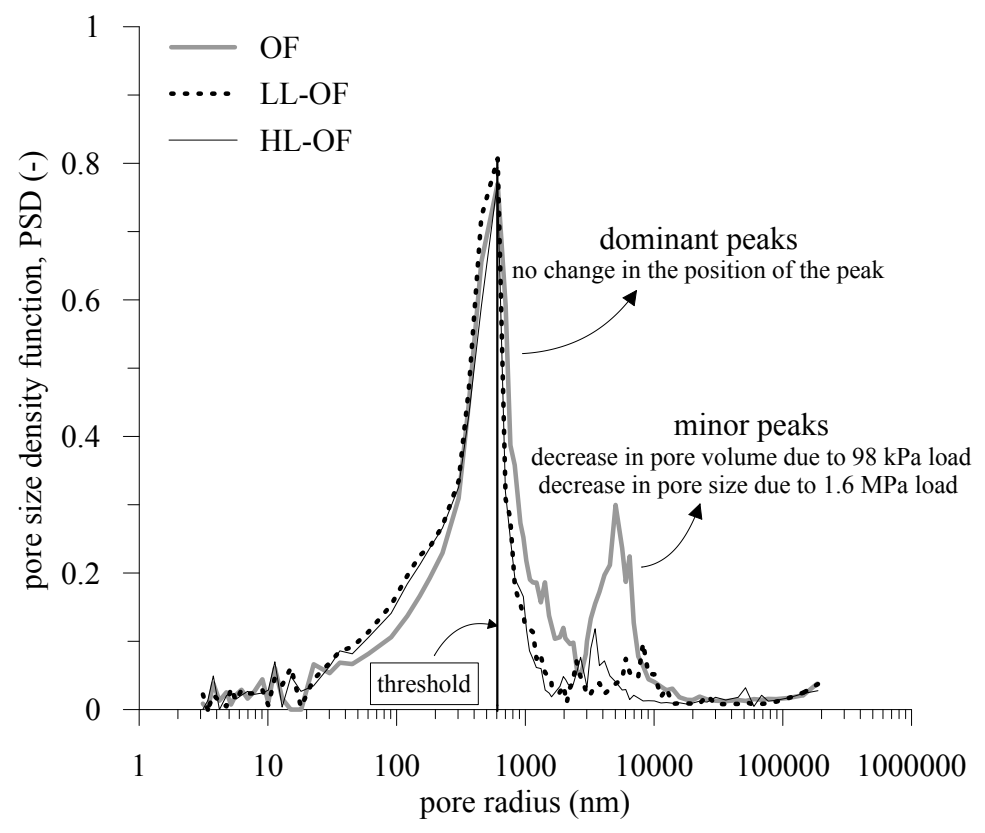

(b) 


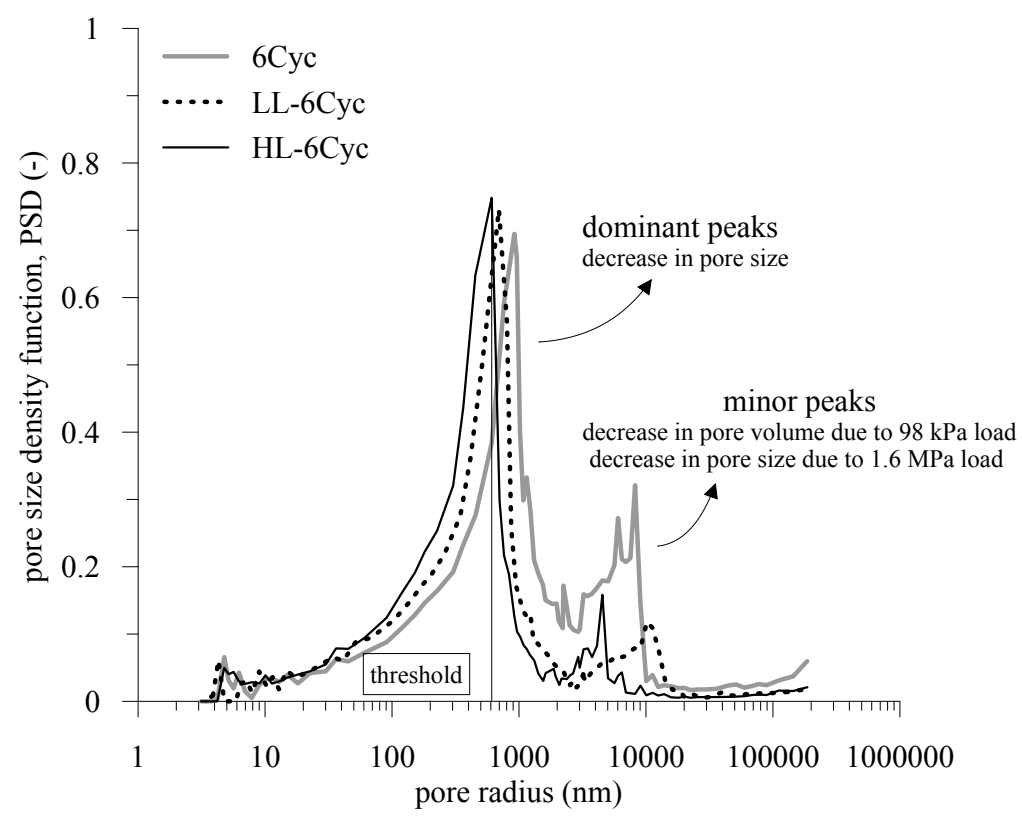

(c)

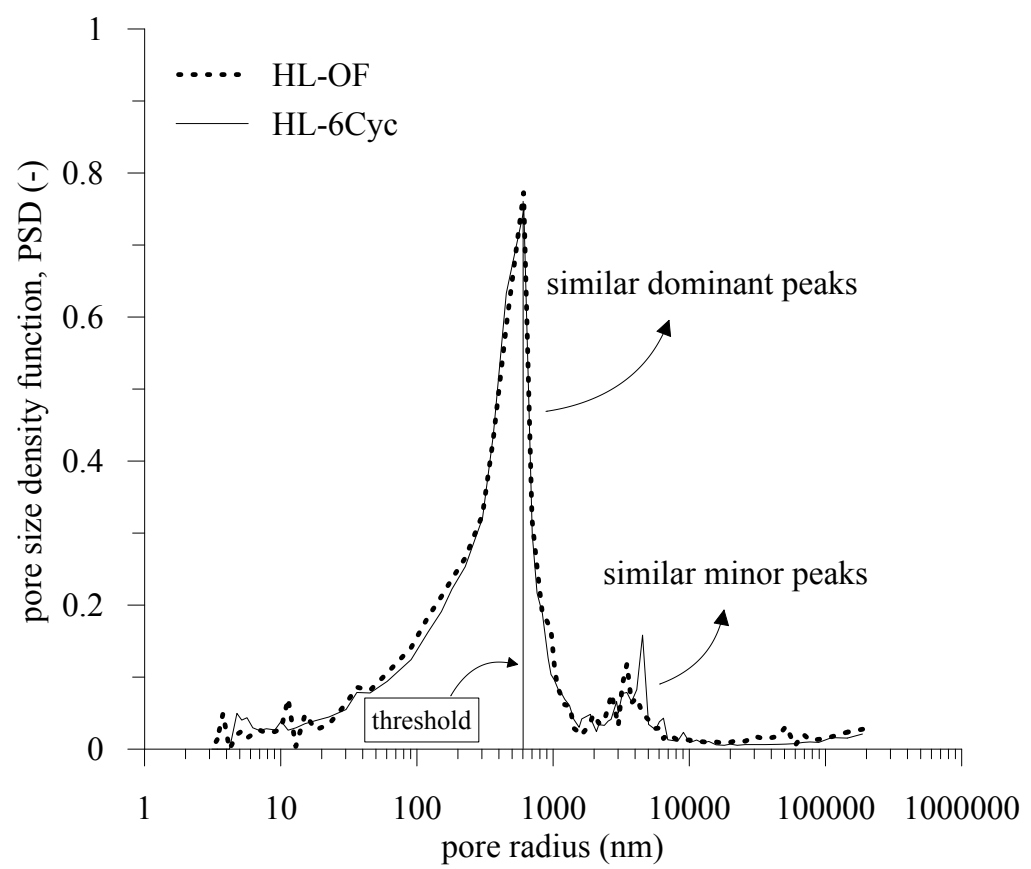

(d)

Fig. 4. Evolution of the PSD with drying-wetting cycles and with mechanical loading: (a) evolving the PSD with drying and wetting; (b) evolving the PSD of OF samples with mechanical loading; (c) evolving the PSD of 6Cyc samples with mechanical loading; (b) the PSDs of OF and 6Cyc samples being subjected to 1.6 MPa. 


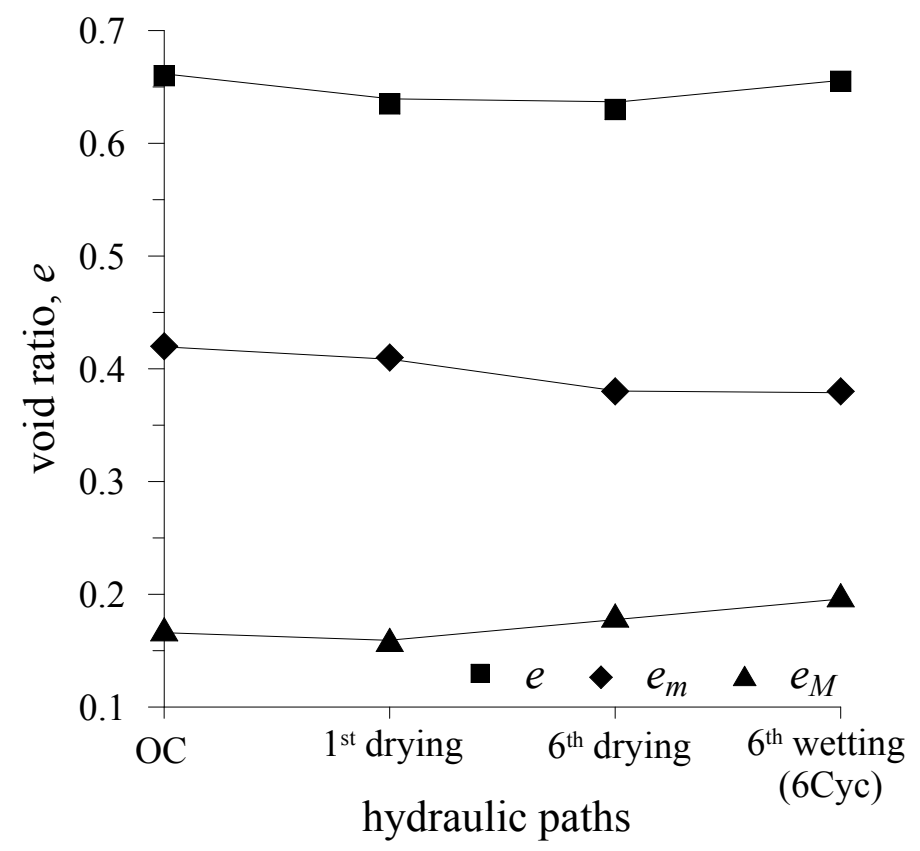

(a)

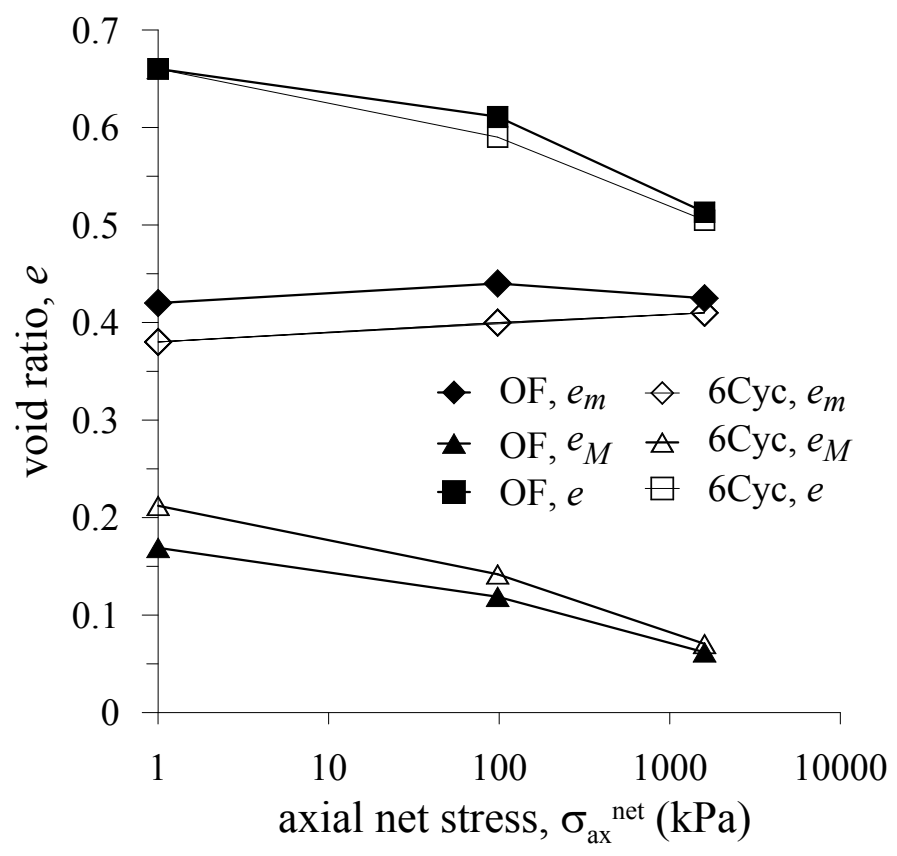

(b)

Fig. 5. Evolution of void ratio $e$, micro-structural void ratio $e_{m}$ and macro-structural void ratio $e_{M}$ : (a) with hydraulic loads; (b) with mechanical loads. 


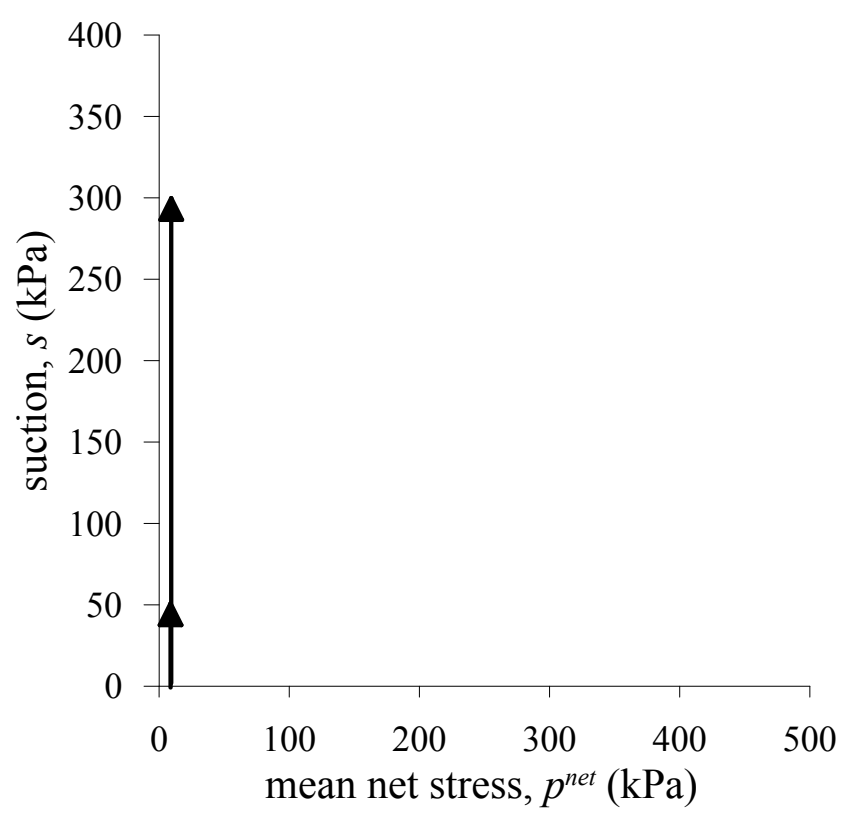

(a)

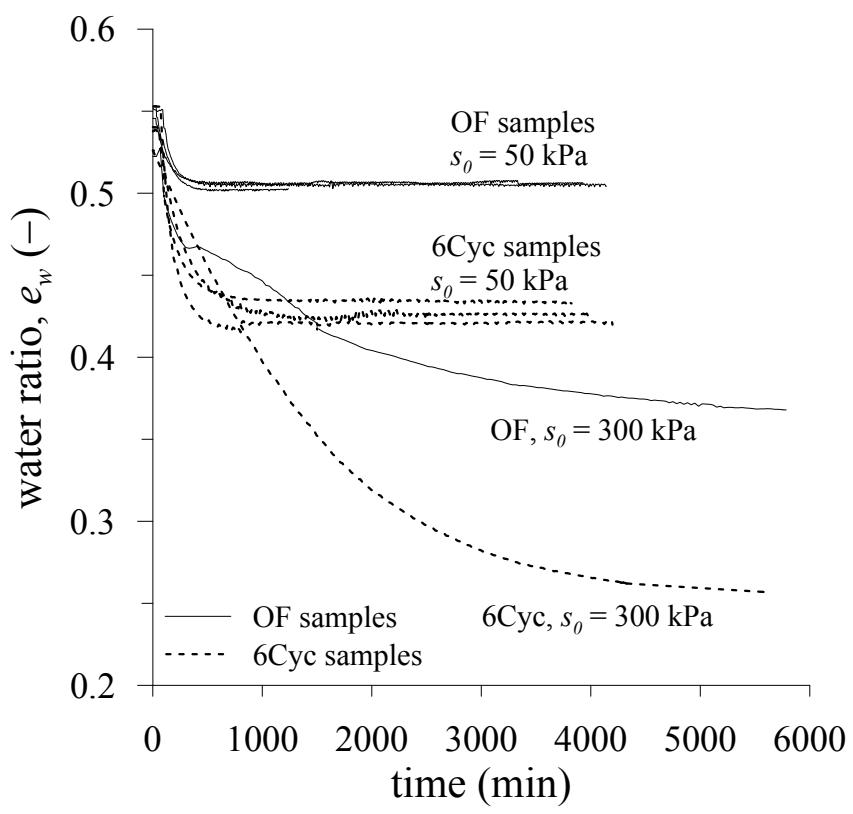

(b) 


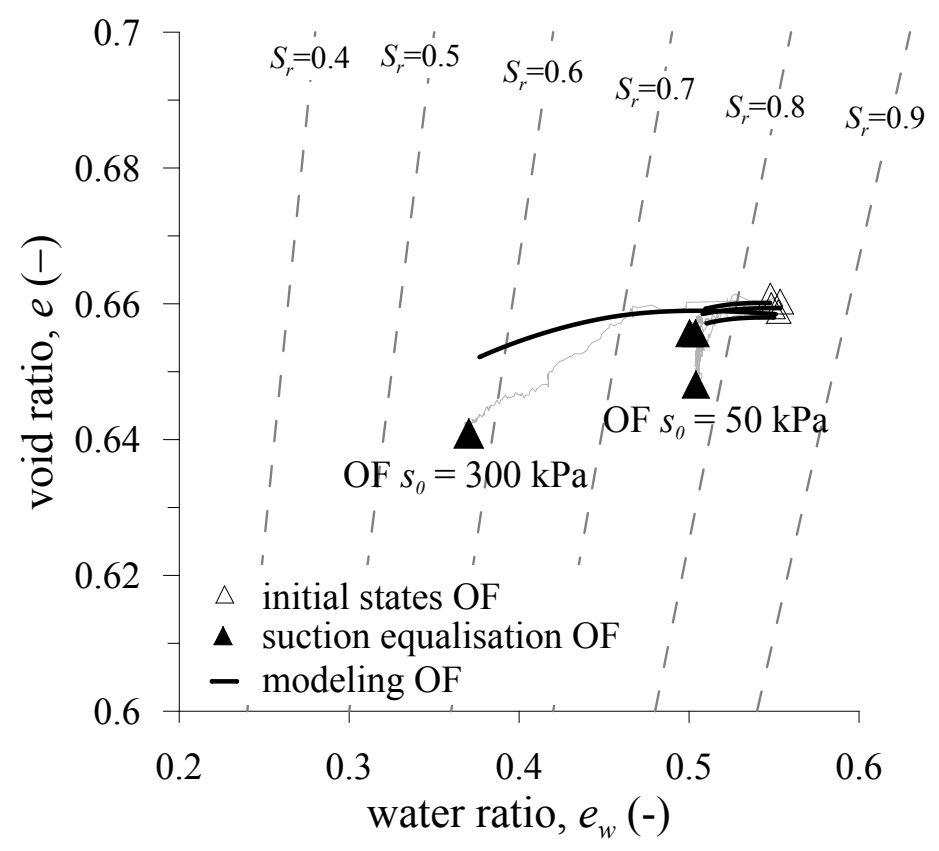

(c)

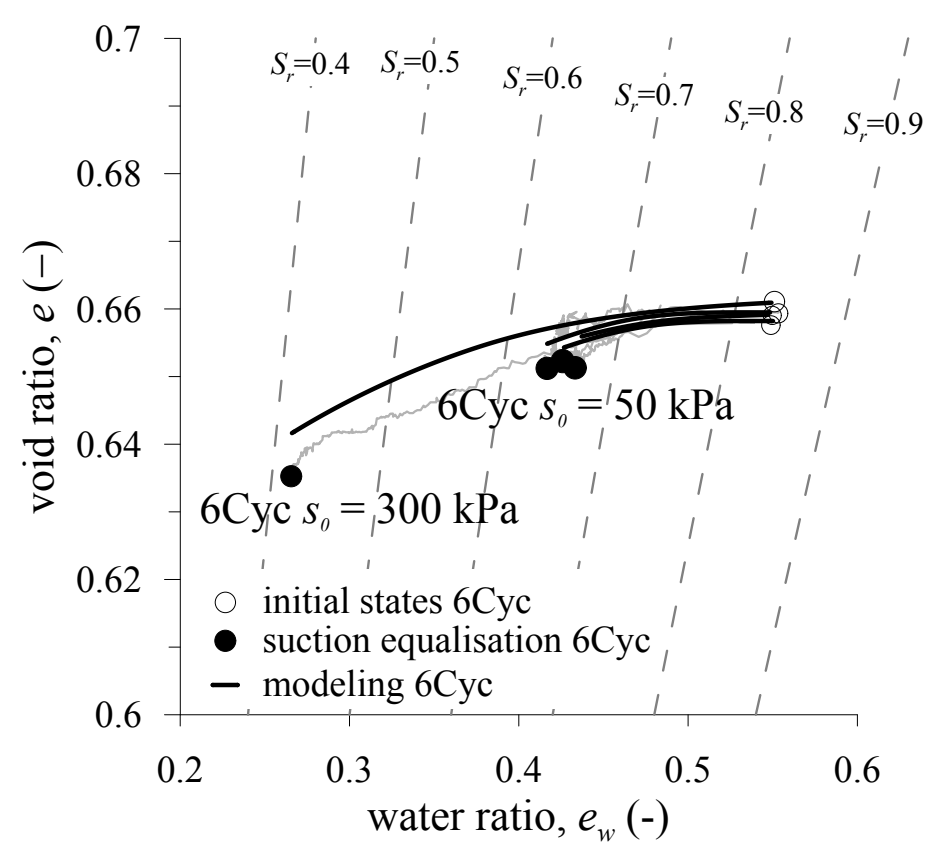

(d) 


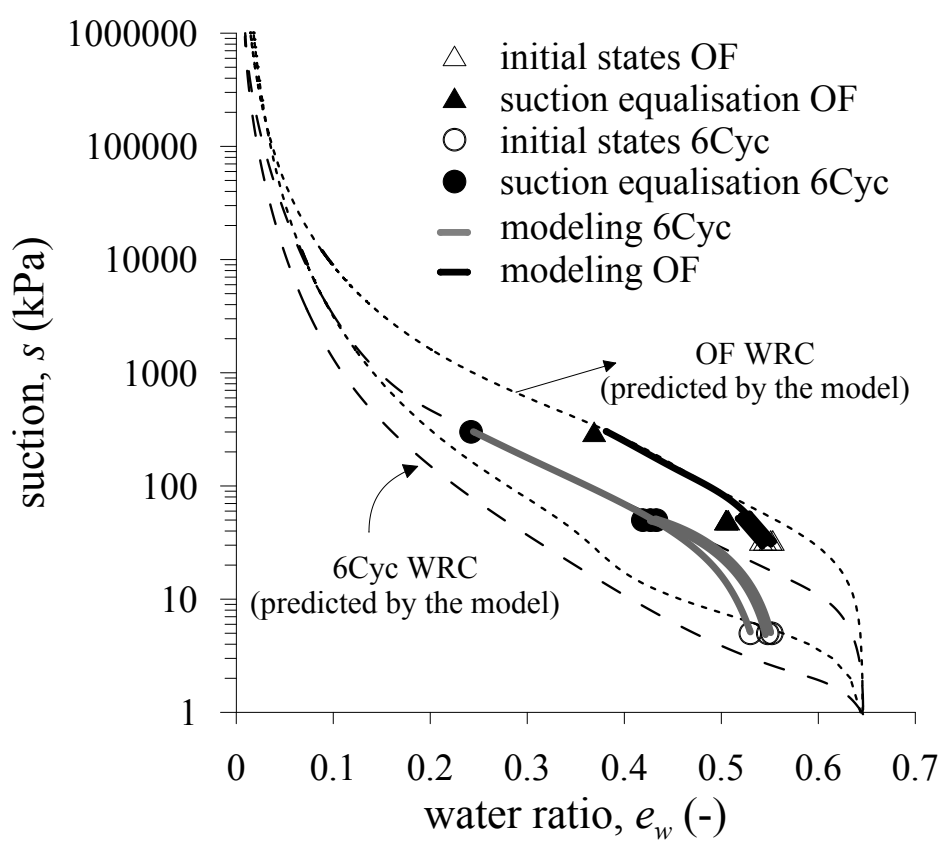

(e)

Fig. 6. Behaviour of samples along drying to 50 and $300 \mathrm{kPa}$ of suction: a) stress and hydraulic paths; b) evolution of water ratio with time; c) void ratio-water ratio OF samples; d) void ratio-water ratio 6Cyc samples; e) suction- water ratio. 


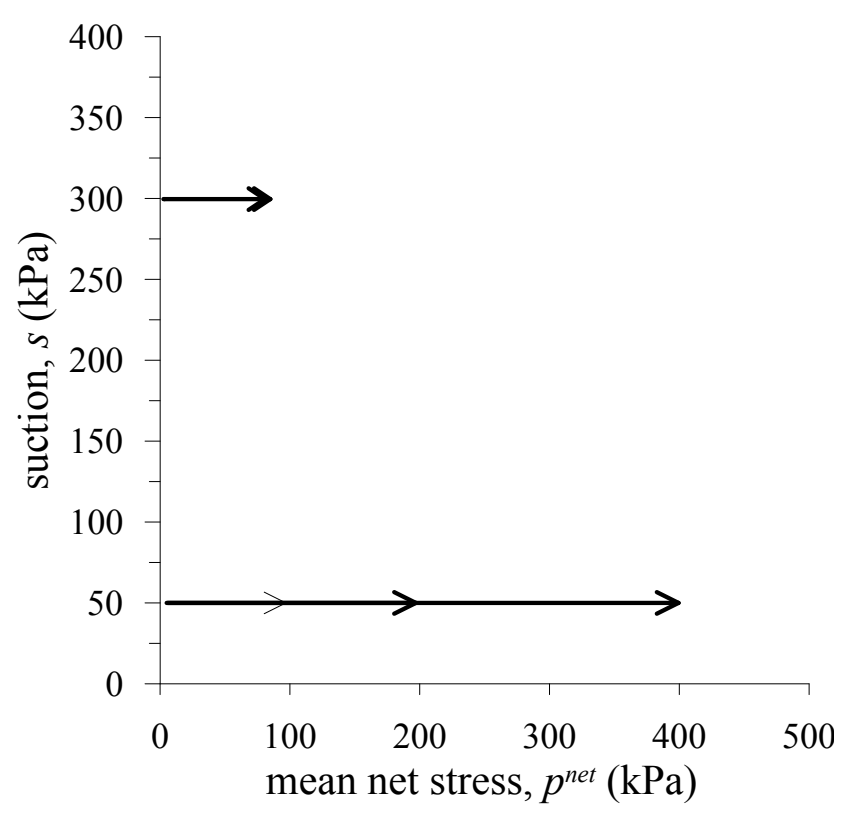

(a)

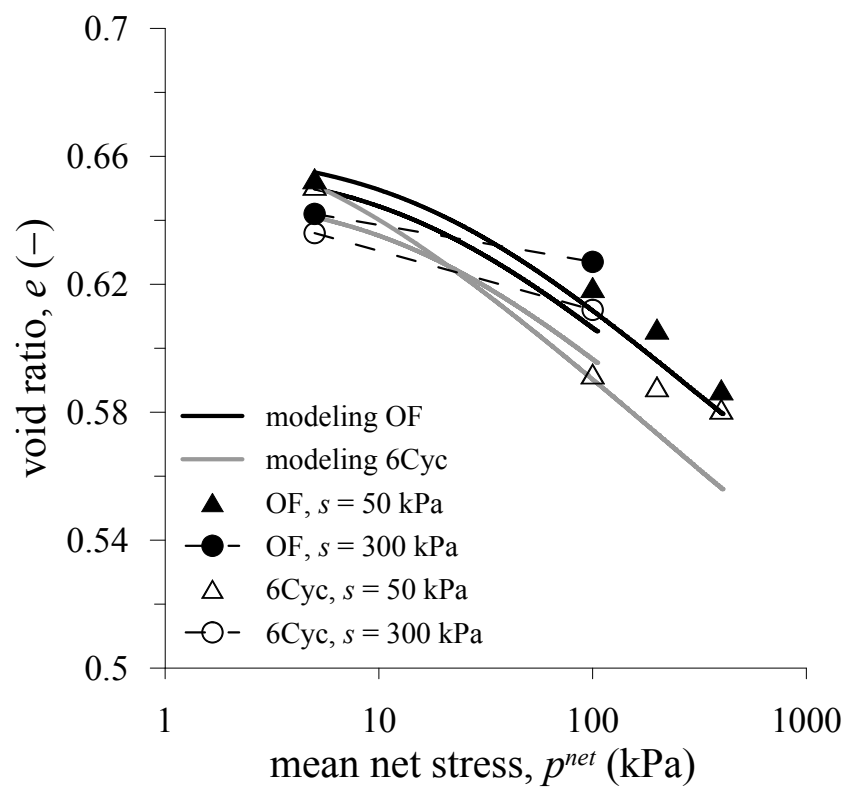

(b)

Fig. 7. Isotropic compression at mean net stress $p^{\text {net }}=100,200$ and $400 \mathrm{kPa}$; a) stress path; b) void ratio- mean net stress. 


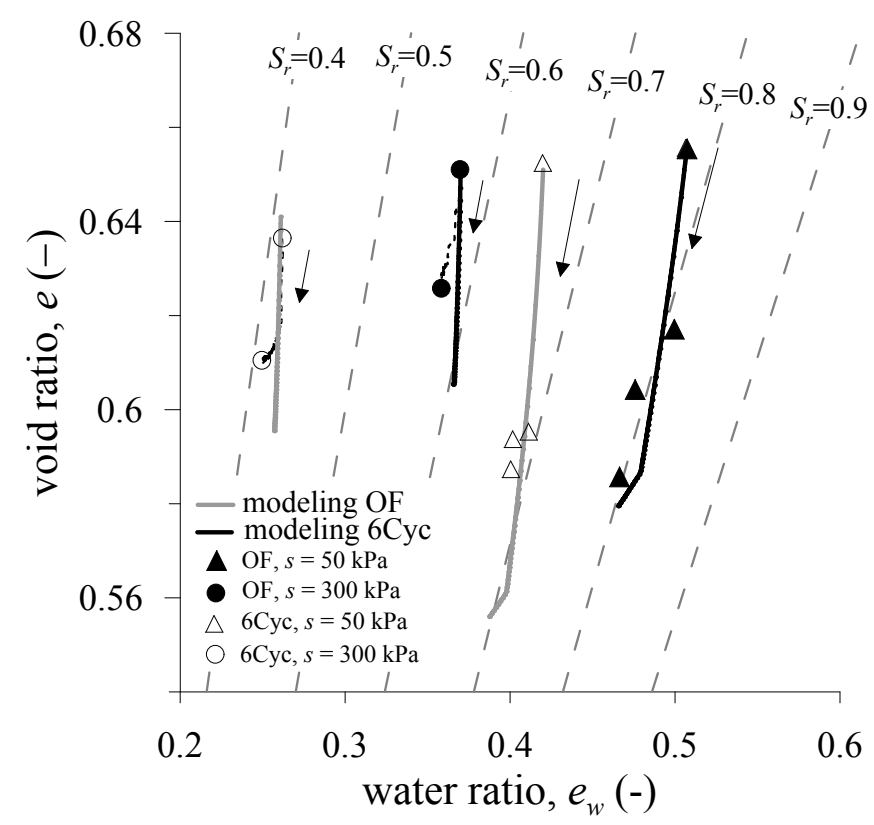

(a)

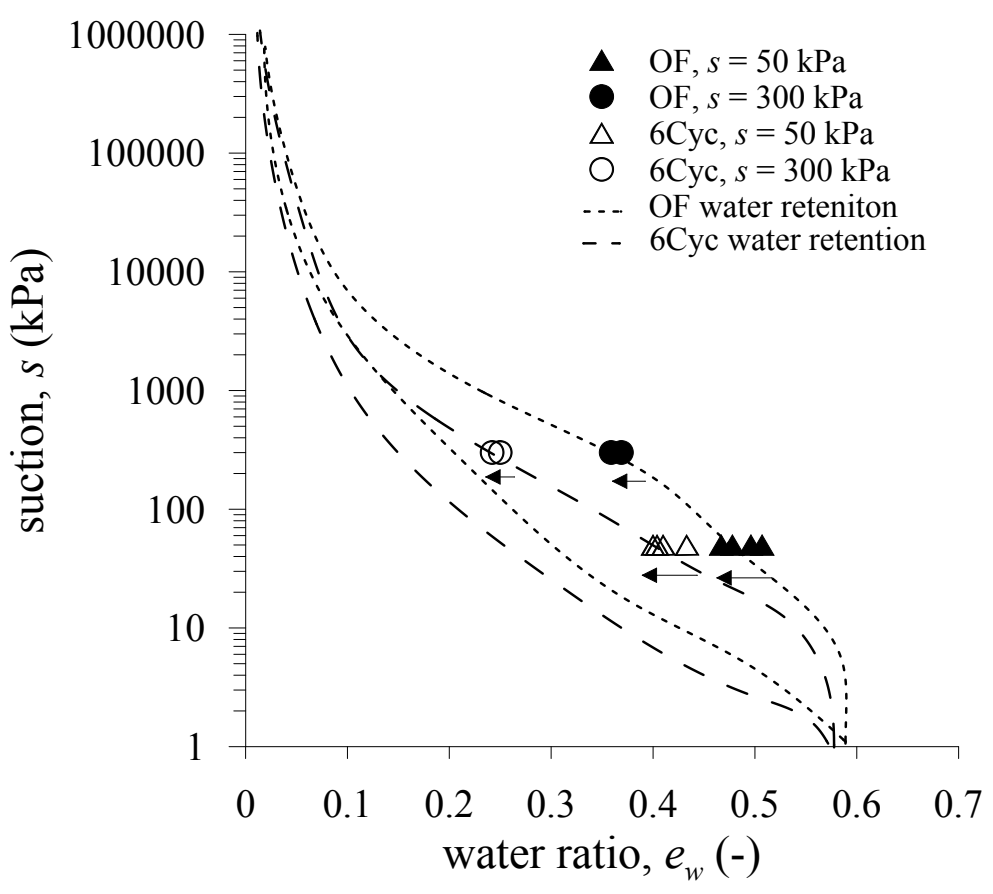

(b)

Fig. 8. Behaviour of OF and 6Cyc samples along isotropic compression to mean net stress of $p^{\text {net }}=100,200$ and 400 $\mathrm{kPa}$ : a) void ratio-water ratio; b) suction-water ratio. 


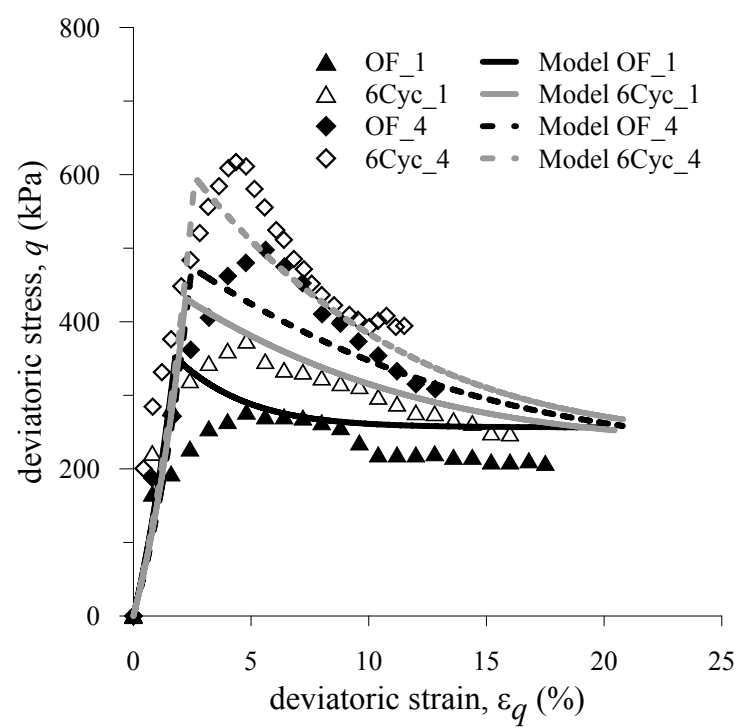

(a)

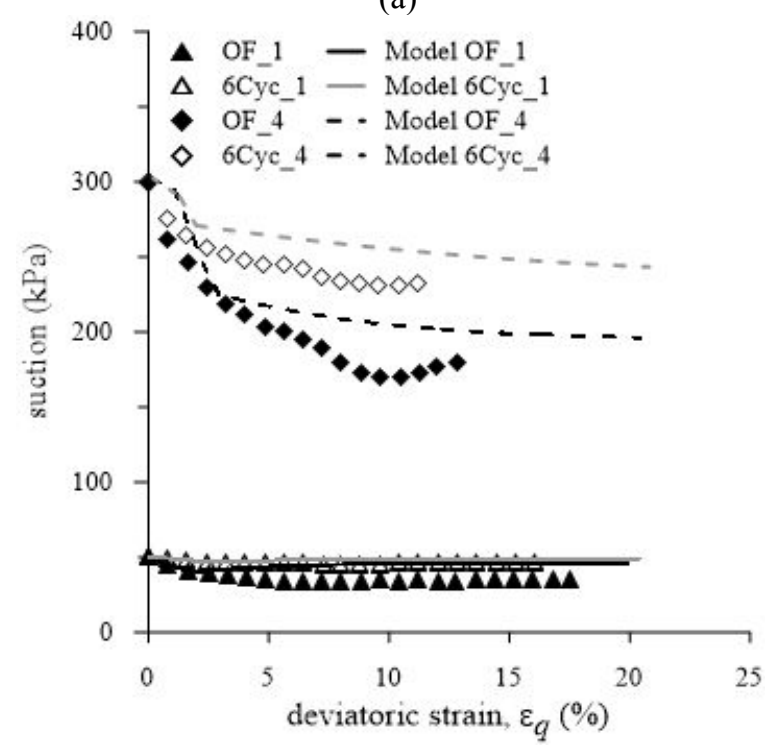

(c)

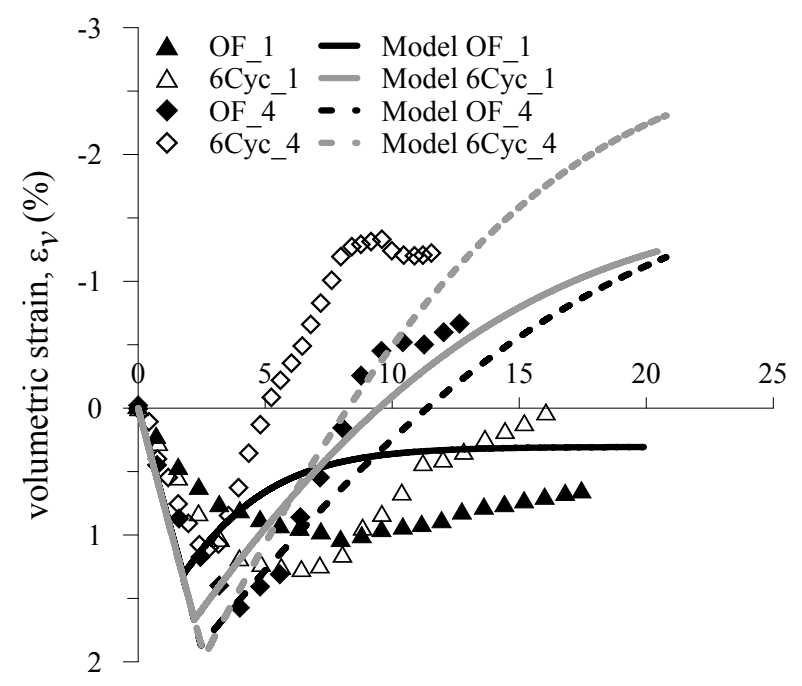

deviatoric strain, $\varepsilon_{q}(\%)$

(b)

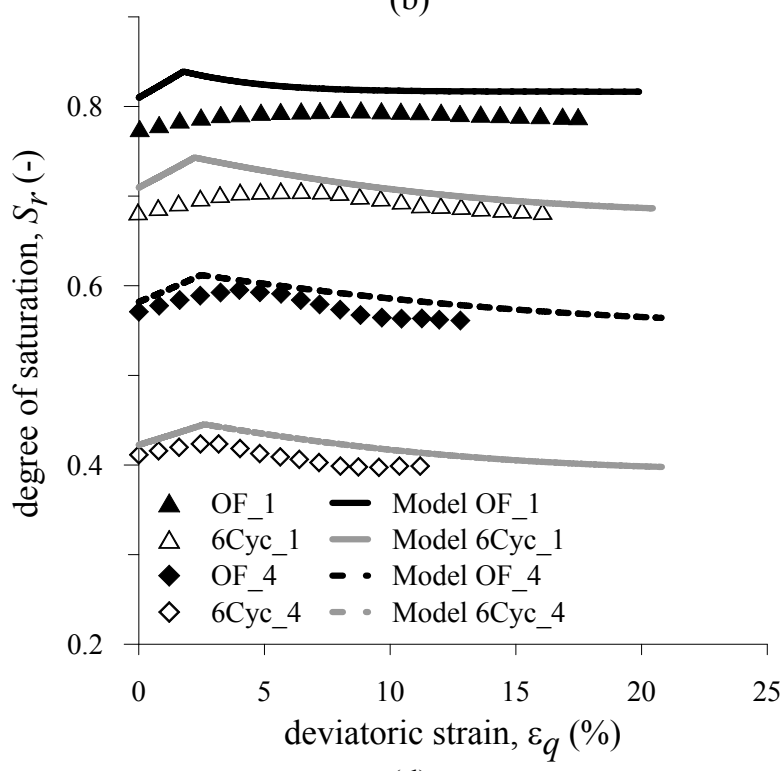

(d)

Fig. 9. Behaviour of OF and 6Cyc samples ( $s_{0}=50$ and $300 \mathrm{kPa}, p^{\text {net }}=100 \mathrm{kPa}$ ) along triaxial compression at constant water content: a) deviatoric stress - deviatoric strains; b) volume strain - deviatoric strain; c) suction - deviatoric strain; d) degree of saturation - deviatoric strain. 


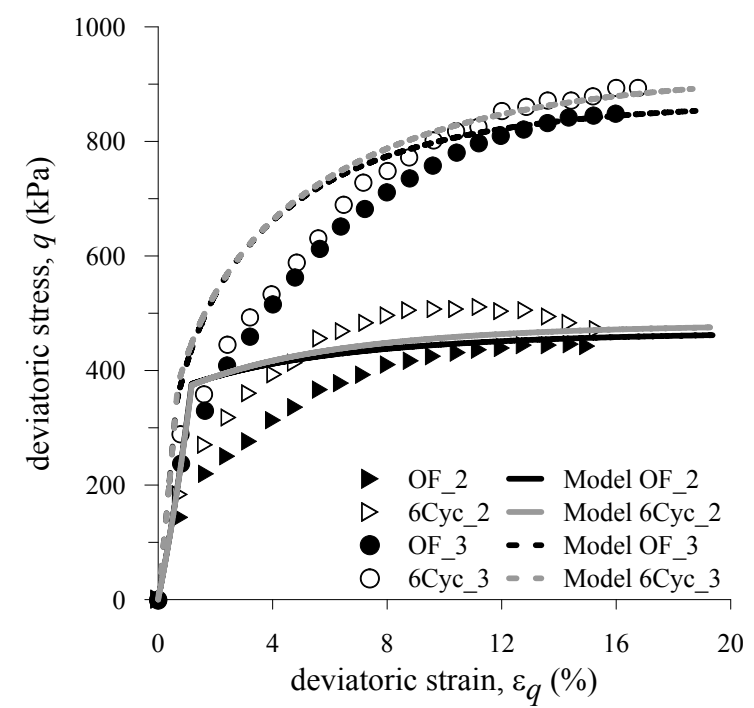

(a)

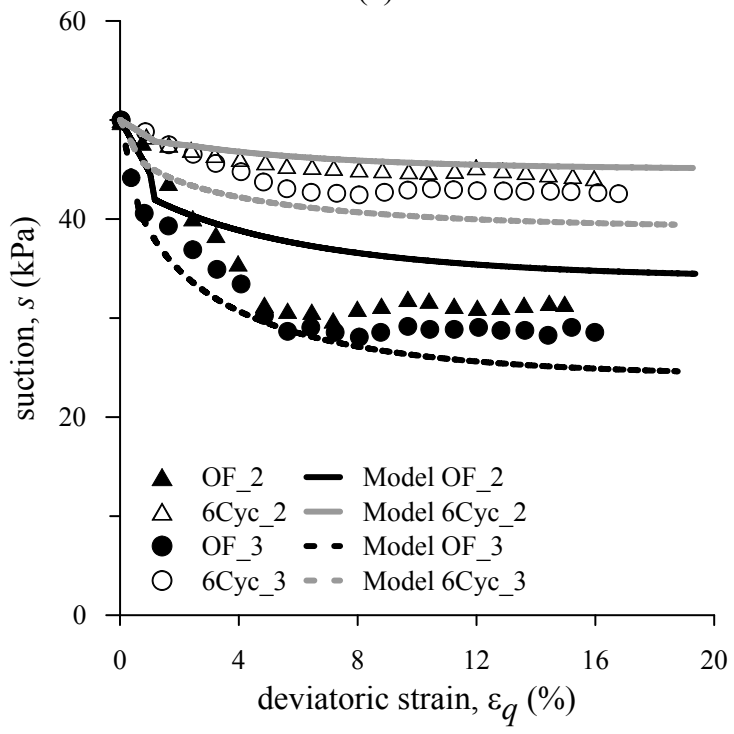

(c)

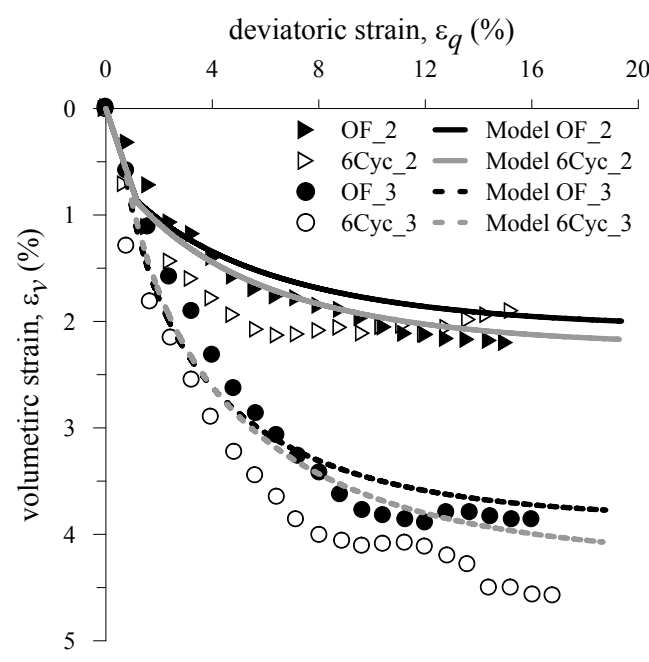

(b)

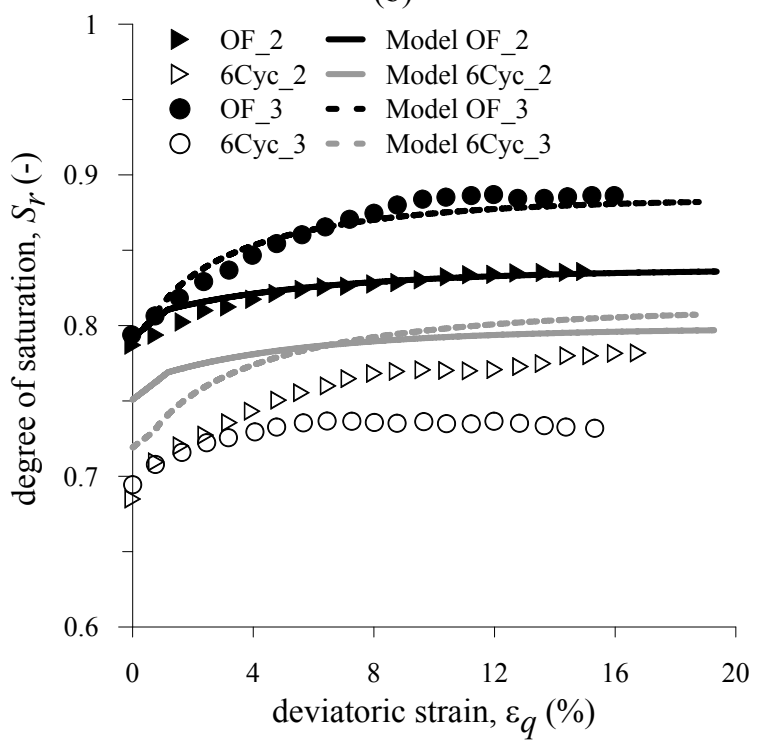

(d)

Fig. 10. Behaviour OF and 6Cyc samples $\left(s_{0}=50 \mathrm{kPa}, p^{\text {net }}=200 \mathrm{kPa}\right.$ and $\left.400 \mathrm{kPa}\right)$ along triaxial compression at constant water content: a) deviatoric stress - deviatoric strains; b) volume strain - deviatoric strain; c) suction deviatoric strain; d) degree of saturation - deviatoric strain. 


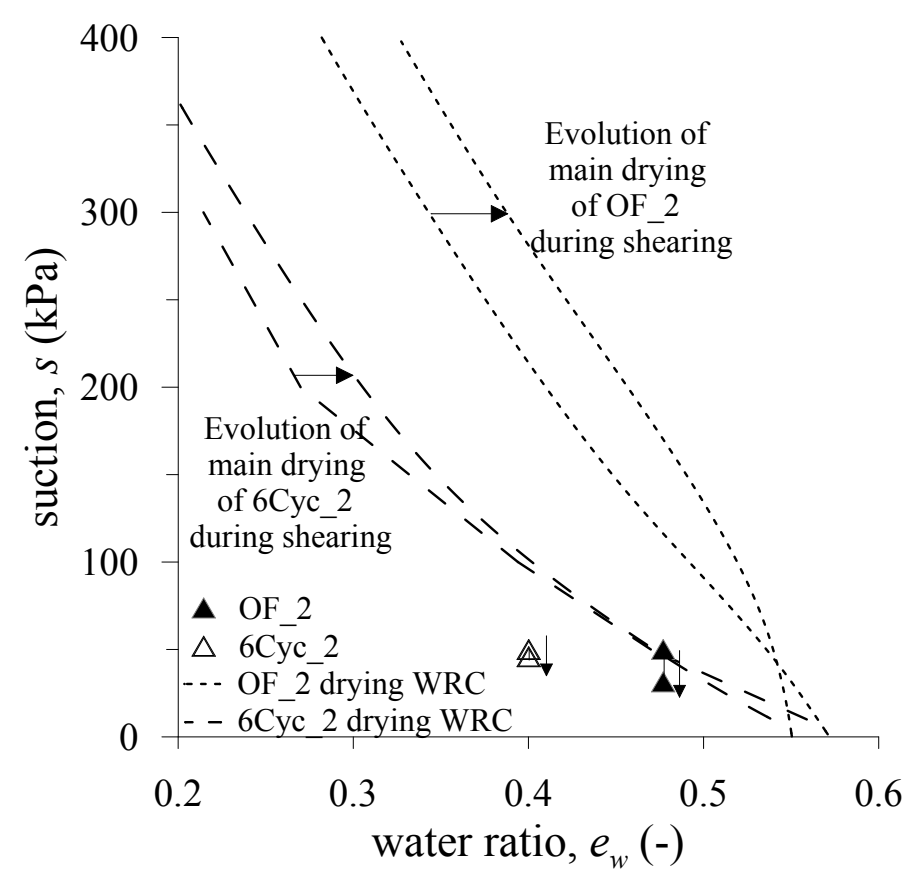

(a)

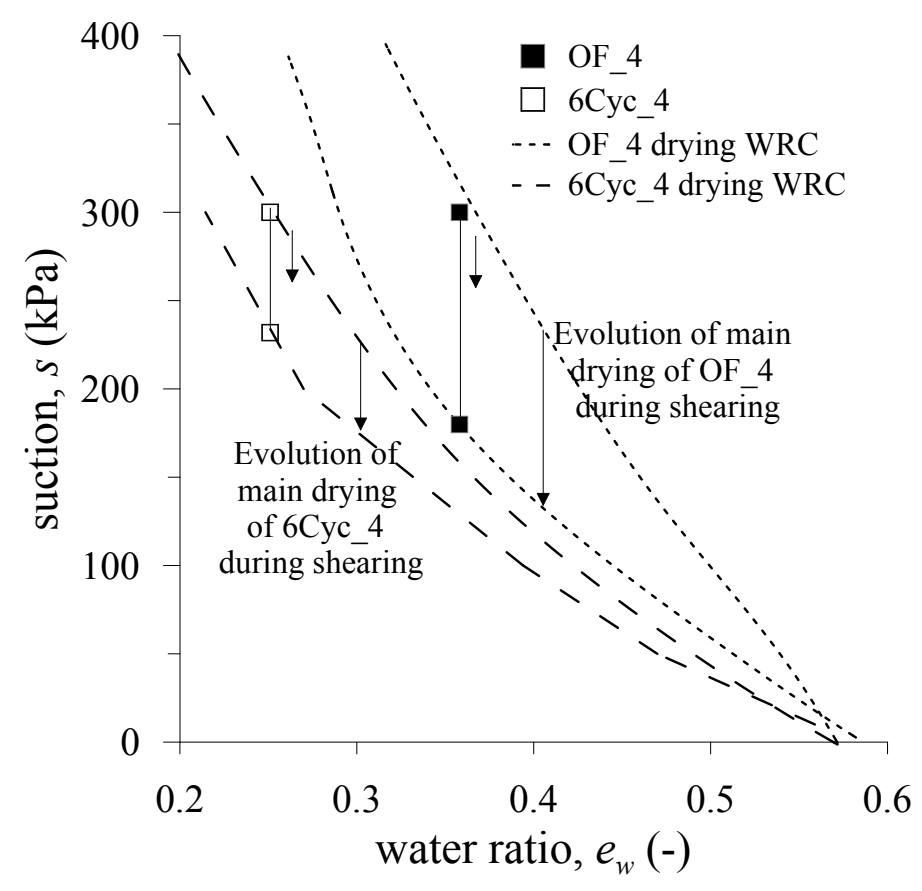

(b)

Fig. 11. Behaviour of OF and 6Cyc samples $\left(s_{0}=50 \mathrm{kPa}\right.$ and $s_{0}=300 \mathrm{kPa}, p_{\text {net }}=100,200$ and $\left.400 \mathrm{kPa}\right)$ during the triaxial compression phase: (a) void ratio-water ratio for samples with $s_{0}=50 \mathrm{kPa}$; b) suction-water ratio for samples with $s_{0}=300 \mathrm{kPa}$. 


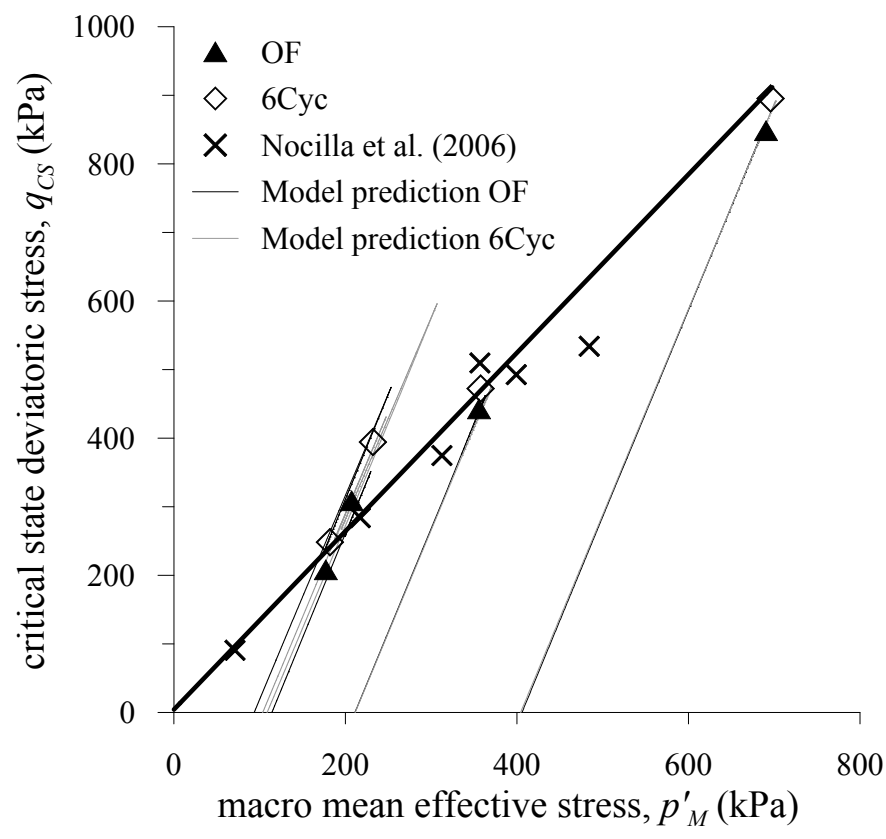

(a)

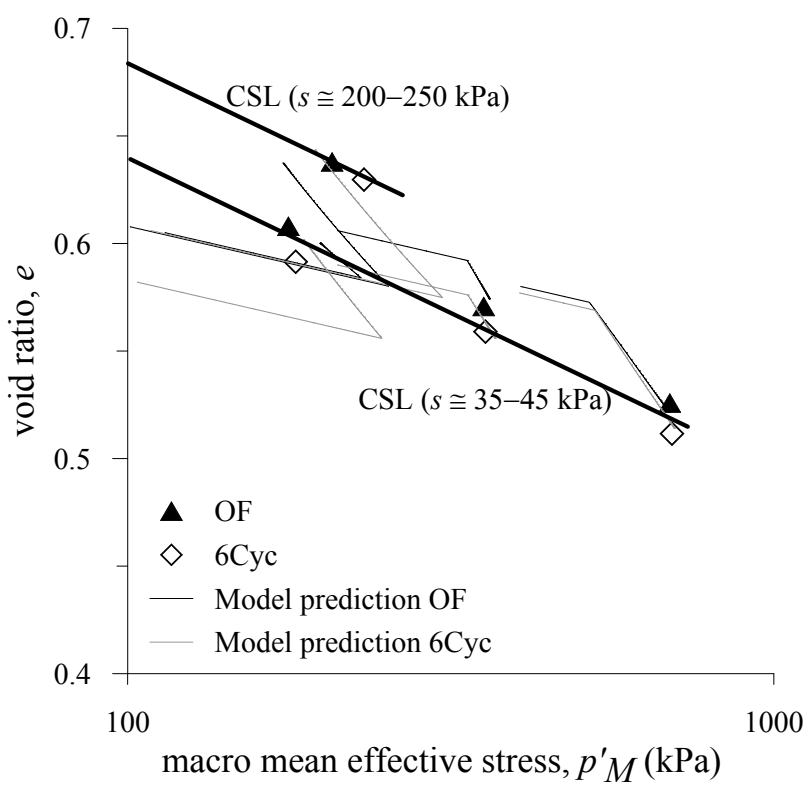

(b)

Fig. 12. Interpretation of final testing conditions and model predictions in terms of macroscopic average skeleton stress of the macrostructure: (a) deviatoric - mean stress plane; (b) compression plane. 


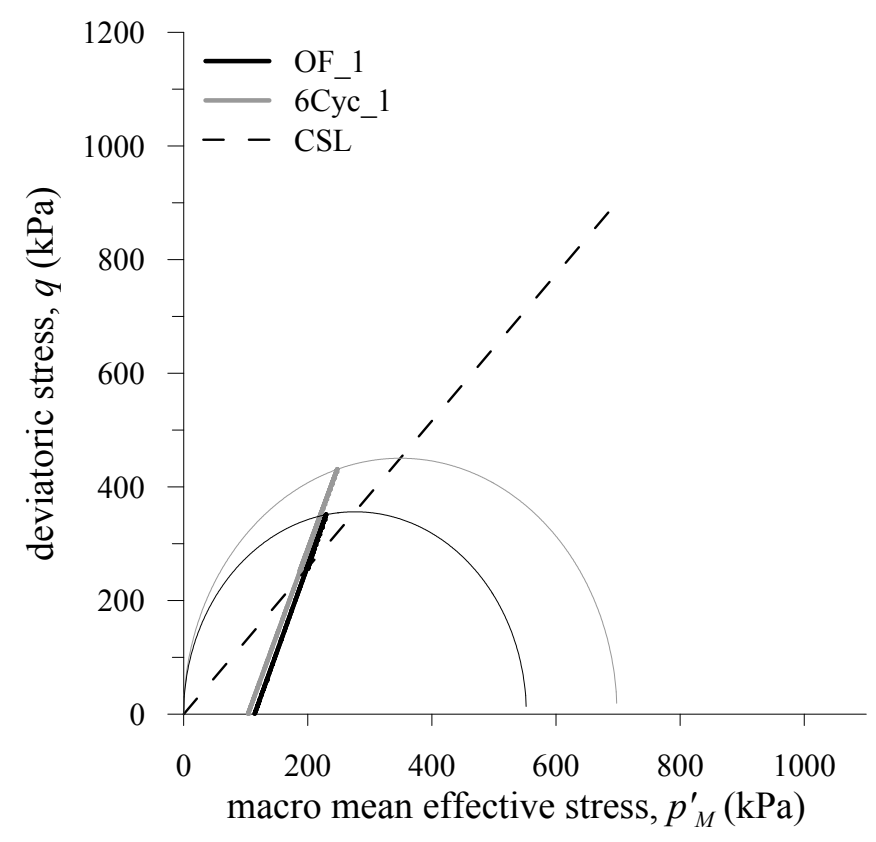

(a)

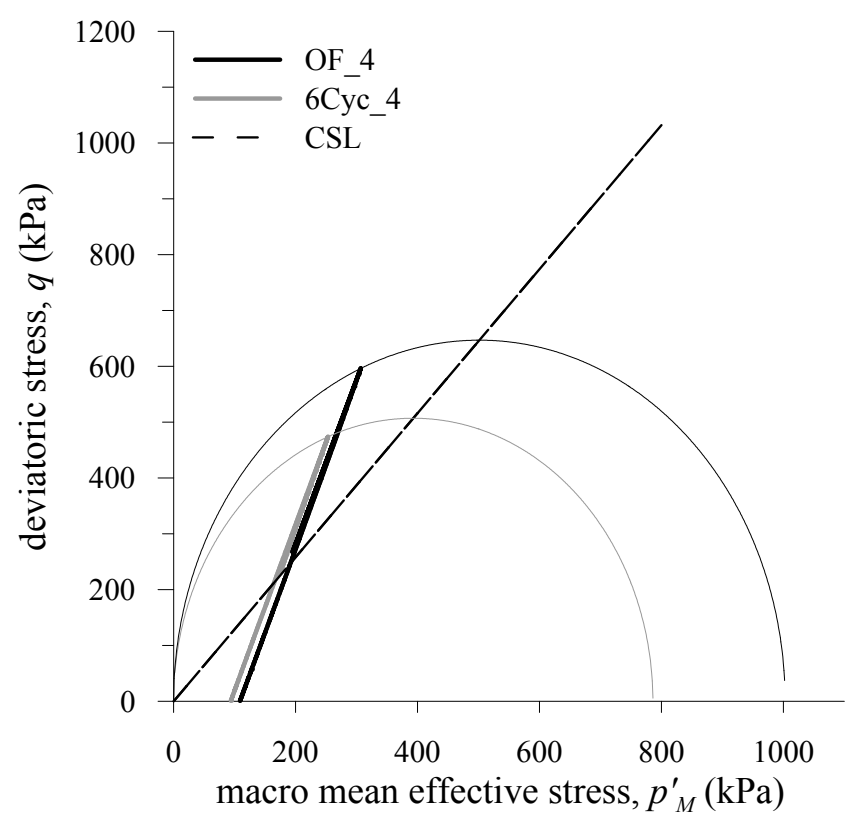

(b)

Fig. 13. Stress paths and initial position of the yield curve: (a) OF_1 and 6Cyc_1 $\left(s_{0}=50 \mathrm{kPa}\right)$; (b) samples OF_4 and 6 Cyc $\_4\left(s_{0}=300 \mathrm{kPa}\right)$. 


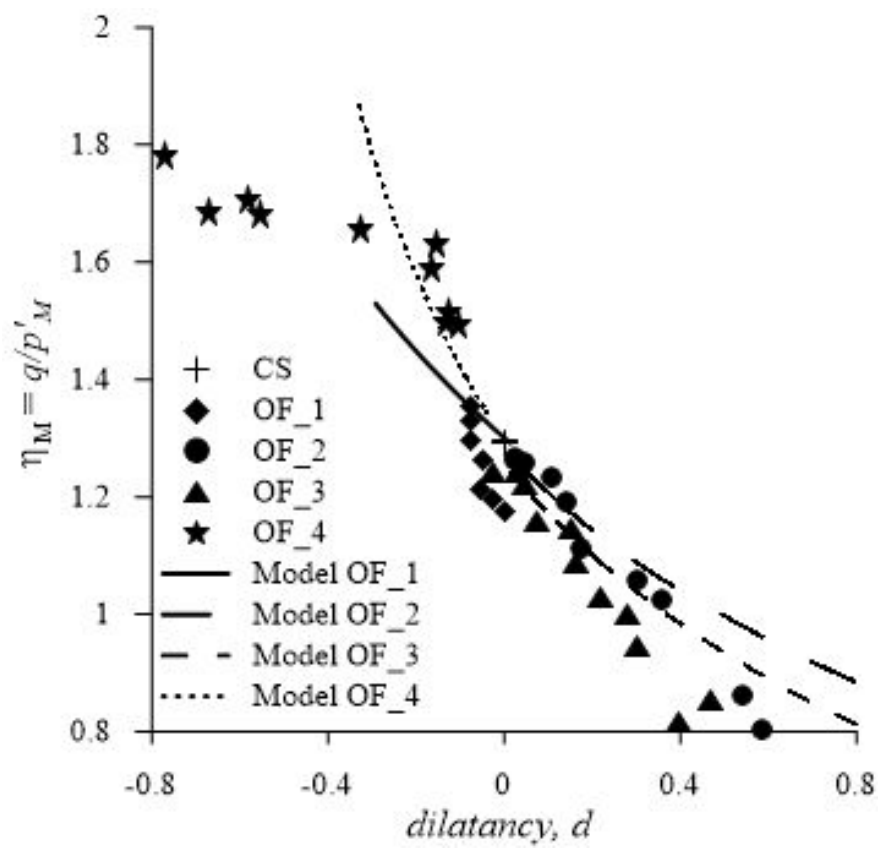

(a)

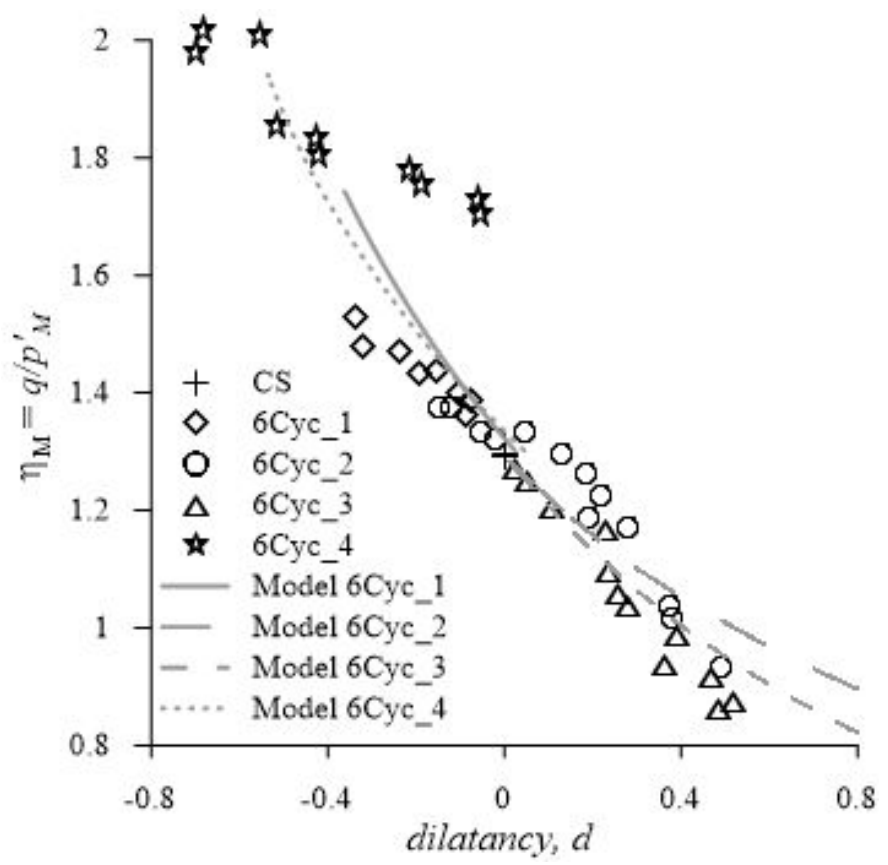

(b)

Fig. 14. Relationship between stress ratio and dilatancy: (a) OF samples; (b) 6Cyc samples. 


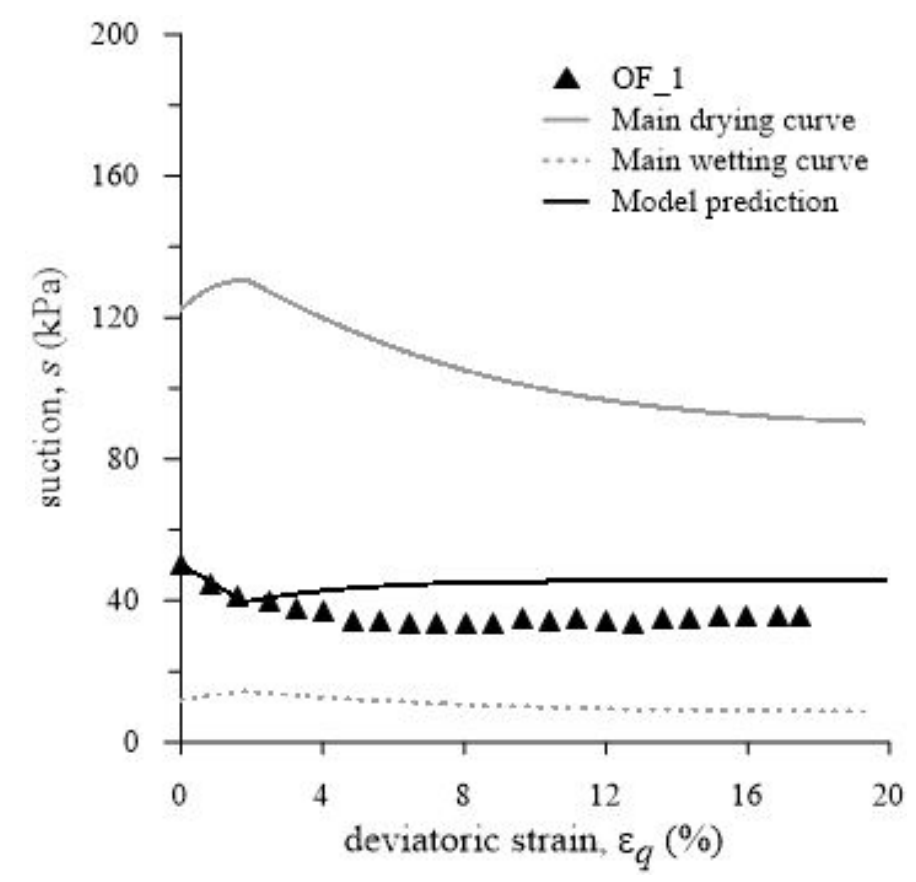

(a)

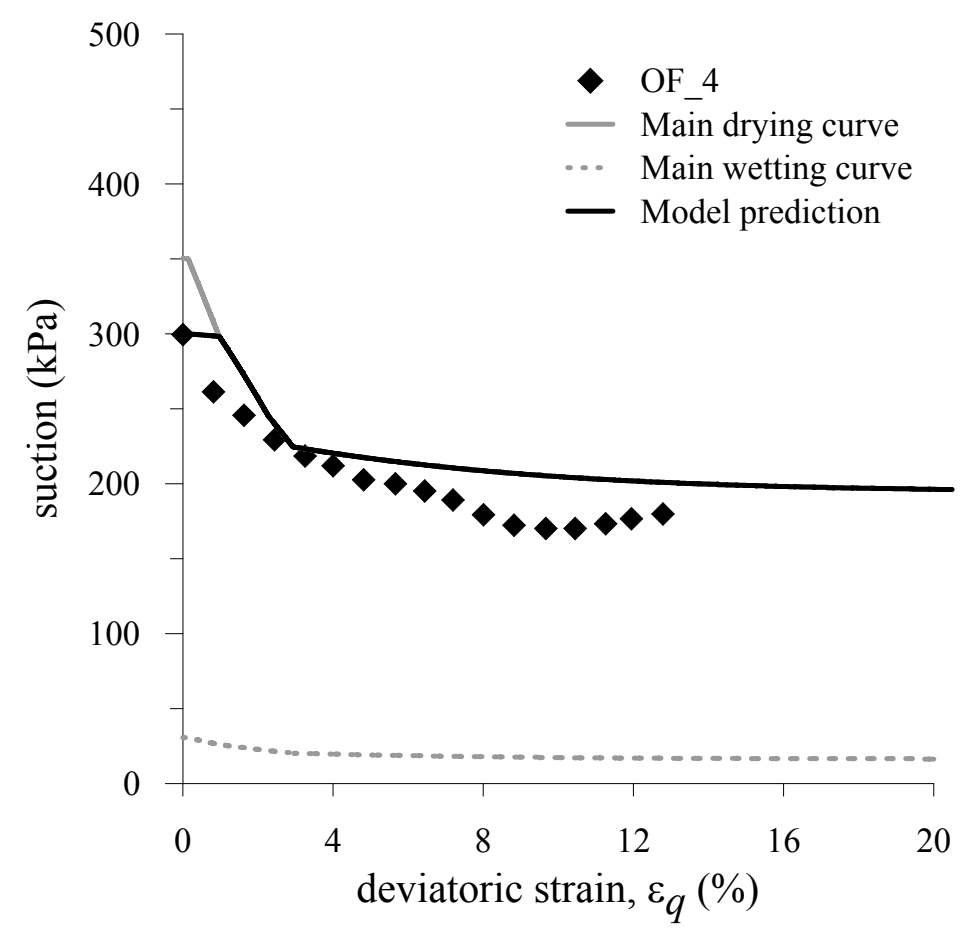

(b)

Fig. 15. Changes in suction and evolution of the points lying on the main drying and main wetting curves: (a) test OF_1 $\left(s_{0}=50 \mathrm{kPa}\right) ;(\mathrm{b}) \mathrm{OF} \_4\left(s_{0}=300 \mathrm{kPa}\right)$. 


\section{Appendix 1 - Experimental techniques}

Drying was imposed by exposing the samples to the laboratory environment, having a controlled temperature of 21 ${ }^{\circ} \mathrm{C}$ and relative humidity of $38.5 \%$ (suction $s=128.8 \mathrm{MPa}$ ). The average water content at the end of drying was $w \approx$ $0.4 \%$. Wetting was imposed by placing the samples in the compaction mould with a basement having a plastic porous disc and water conduits. The water was injected at a rate of about $500 \mathrm{~mm}^{3} / \mathrm{h}$ to bring the water content back to its initial value $(w \cong 20 \%)$. Vertical deformations were allowed during wetting while radial ones were constrained by the steel frame. At the end of wetting the samples were dismantled, wrapped up in plastic bags and held in a sealed humid container for at least 5 days to ensure water equalisation.

All the MIP specimens (height and diameter of about $10 \mathrm{~mm}$ ) were previously freeze-dried to preserve the soil fabric at its natural water content (Delage and Pellerin 1984). A Micromeritics AutoPore IV 9500 was used, injecting mercury into to pore network under vacuum condition. The relationship between the apparent pore radius $(r)$ and the absolute injection pressure $(p)$ was obtained through Washburn's equation:

$$
r=-\frac{2 \sigma^{H g} \cos \theta_{n w}}{p}
$$

where $\sigma^{H g}=0.484 \mathrm{~N} / \mathrm{m}$ at $25^{\circ} \mathrm{C}$ is the surface tension of the mercury and $\theta_{n w}=140^{\circ}$ is the contact angle between the mercury and the pore wall.

The MIP tests were interpreted in terms of pore size density function (PSD) defined at log $r$ :

$$
P S D=f(\log r)=\frac{p d\left(V_{v 0}-V_{v}\right)}{\log e \quad V_{v 0} d p}
$$

where $e$ is void ratio, $V_{v 0}$ is the total volume of pores and $\left(V_{v 0}-V_{v}\right)$ is the volume of intruded mercury or the volume of pores with radius equal or greater than $r$.

The hydromechanical response along drying, isotropic and triaxial compression was studied with a suctioncontrolled triaxial cell, adopting the axis translation technique. The top and bottom caps at both sides of the specimen were equipped with two concentric porous stones, one for each fluid of concern (air and water). The inner porous stone, a ceramic disc having an Air Entry Value of $500 \mathrm{kPa}$ in the $s_{0}=300 \mathrm{kPa}$ tests and an Air Entry Value of $100 \mathrm{kPa}$ in the $s_{0}=50 \mathrm{kPa}$ tests, was connected to the water line and it was used to impose the water pressure. The external porous stone, a stainless steel coarse porous ring, was used to impose the air pressure. Local axial displacements were measured on the side of the samples by two miniature LVDTs. An external LVDT contrasted to 
the loading ram measured large and necessary displacements. Radial displacements were measured using electrooptical laser sensors mounted outside of the cell, on opposite sides of the sample (as e.g. in Romero 1999).

The triaxial tests consisted of three stages including suction equalization, isotropic and triaxial compression. First the desired suction $\left(s_{0}=50 \mathrm{kPa}\right.$ or $s_{0}=300 \mathrm{kPa}$ ) was imposed through the axis translation technique while applying a small net mean pressure $p^{\text {net }}$. The sample was being held to equalize at constant suction until the changes in water content and volume were stabilized.

During isotropic compression, the net mean pressure was increased to the predefined values (100, 200 or $400 \mathrm{kPa})$ under a free drainage condition while the suction was kept constant. The net pressure was increased at the rate of 50 $\mathrm{kPa} / \mathrm{h}$ while the deviatoric stress was maintained smaller than $5 \mathrm{kPa}$, providing isotropic conditions.

During triaxial compression at the constant water content condition, the water drainage was prevented and the pore water pressure was measured by means of a pressure transducer connected to the water porous stone, while the air pressure was kept constant. A constant axial strain rate of $0.25 \% / \mathrm{h}$ was imparted to ensure that the measured water pressure was in equilibrium with the sample. The cell pressure was kept constant and the axial force was measured. 